\title{
Current and emerging drugs for the treatment of inflammatory bowel disease
}

\author{
This article was published in the following Dove Press journal: \\ Drug Design, Development and Therapy \\ 5 April 2011 \\ Number of times this article has been viewed
}

\author{
John K Triantafillidis \\ Emmanuel Merikas \\ Filippos Georgopoulos \\ Department of Gastroenterology, \\ Center for Inflammatory Bowel \\ Disease, "Saint Panteleimon" General \\ Hospital, Nicea, Greece
}

\begin{abstract}
During the last decade a large number of biological agents against tumor necrosis factor- $\alpha$ (TNF- $\alpha$ ), as well as many biochemical substances and molecules specifically for the medical treatment of patients with inflammatory bowel disease (IBD), have been developed. This enormous progress was a consequence of the significant advances in biotechnology along with the increased knowledge of the underlying pathophysiological mechanisms involved in the pathogenesis of IBD. However, conventional therapies remain the cornerstone of treatment for most patients. During recent years conventional and biologic IBD therapies have been optimized. Newer mesalazine formulations with a reduced pill size and only one dose per day demonstrate similar efficacy to older formulations. New corticosteroids retain the efficacy of older corticosteroids while exhibiting a higher safety profile. The role of antibiotics and probiotics has been further clarified. Significant progress in understanding thiopurine metabolism has improved the effective dose along with adjunctive therapies. Quite a large number of substances and therapies, including biologic agents other than TNF- $\alpha$ inhibitors, unfractionated or lowmolecular-weight heparin, omega-3 polyunsaturated fatty acids, microbes and microbial products, leukocytapheresis, and other substances under investigation, could offer important benefits to our patients. In this paper we review the established and emerging therapeutic strategies in patients with Crohn's disease and ulcerative colitis.
\end{abstract}

Keywords: inflammatory bowel disease, ulcerative colitis, Crohn's disease, treatment, biologic agents, immunosuppressives, mesalazine, antibiotics

\section{Introduction}

Inflammatory bowel disease (IBD) is a chronic, relapsing, inflammatory disorder of the gastrointestinal tract that includes two entities, namely Crohn's disease (CD) and ulcerative colitis (UC). In the last decade, our understanding of the etiology and pathogenesis of IBD has improved considerably.

Treatment of the disease includes conservative measures as well as surgical approaches in those who are non-responders to medical treatment. The primary therapeutic goals are related to improvement of patient quality of life by inducing and maintaining remission, predicting, preventing and treating complications, restoring nutritional deficits, providing appropriate psychosocial support, and modifying the course in those with aggressive disease.

Pharmaceutical treatment of IBD includes five major categories, namely antiinflammatory drugs, immunosuppressants, biologic agents, antibiotics, and drugs for symptomatic relief. Several other pharmaceutical substances have been produced and studied in recent years, the implementation of which was the result of an 
increased knowledge of the underlying pathophysiological mechanisms.

There is now a general consensus that IBD is the result of the combined effects of 4 factors: environmental influences, genetic variations, intestinal microbiota alterations, and disturbances in the innate and adaptive immune responses. A combination of all these factors is probably necessary for the disease to be clinically expressed. However, it seems that each patient has a different combination of factors leading to the disease, explaining why each patient displays their own clinical picture and response to therapy. ${ }^{1}$

The intestine is the largest lymphoid organ in the body because of the huge antigen load to which it is exposed on a daily basis. The mucosa-associated lymphoid tissue of the bowel is regulated by unique mechanisms, as reflected in oral tolerance, physiologic inflammation, and intraepithelial lymphocytes that respond to alternative pathways of activation. Moreover, the existence of novel antigen-presenting cells is responsible for distinct immune responses.

Altered immune responses are considered to be quite important elements related to the pathogenesis of IBD. The innate immune system plays a significant role in the defense mechanisms by recognizing bacterial products and cellular signaling. The abnormal signaling pathways can lead to dysregulation of the inflammatory response. Impairment of this system results in activation of the adaptive immune system leading to excessive proinflammatory cytokine production derived from CD4+ T cells over and above the response normally associated with tolerance and immunoregulation. ${ }^{2}$

Intestinal epithelial cell barrier function is also considered to be an important part of the immune defense of the host. Inappropriate access of antigens to the mucosal immune system through dysfunctional barrier function represents an important element in the IBD pathophysiology.

Genetic predisposition affects the regulation of innate and adaptive immunity. Therefore, immunogenetic pathways associated with innate and adaptive immunity, cytokines secreted by innate and adaptive immune cells, epithelial and leukocyte factors, and structures on the endothelium that regulate the recruitment of leukocytes define pathways that could be therapeutic targets.

There are some differences between CD and UC in the underlying immunological disturbances. In CD the antigen presenting cells and macrophages produce mainly interleukin-12 (IL-12) and IL-18 resulting in a Th1-type polarization and production of pro-inflammatory cytokines including tumor necrosis factor- $\alpha$ (TNF- $\alpha$ ), interferon- $\gamma$ (IFN- $\gamma$ ), and IL-2. Subsequently these cytokines stimulate the antigen presenting cells to secrete other cytokines including IL-1, IL-6, IL-8, IL-12, and IL-18, thus leading to a self-sustained cycle. ${ }^{3}$

Patients with UC exhibit an added contribution of Th2 responses characterized by increased secretion of IL-4, IL-5, and IL-13 and reduced amounts of IFN- $\gamma$. Th17 cells were identified as a new subset of T helper cells unrelated to Th1 or Th2 cells. Th17 cells differentiate under the influence of IL-1 $\beta$, IL-6, IL-2 1 and IL-23. ${ }^{4}$ Recently it was shown that transforming growth factor- $\beta$ (TGF- $\beta$ ) regulates also the differentiation of Th17 cells, with the presence of cytokines favoring Th17 cell differentiation. ${ }^{5}$

Additionally, other molecules involved in leukocyte trafficking (adhesion molecules), chemokines, and tissue repair molecules are also crucial in the pathogenesis of the disease. In IBD continuous production of pro-inflammatory cytokines results in an inappropriately increased adhesion molecule expression, as well as in an aberrant expression of molecules not normally expressed by specific lymphocyte subpopulations. ${ }^{6}$

In recent years the knowledge of all these complex pathophysiological processes has resulted in the implementation of a number of different pharmaceutical agents in the treatment of IBD. These drugs were designed to minimize the inflammatory process through inhibition of different targets.

In this review we will try to describe the established and emerging therapeutic strategies in patients with IBD.

\section{Drugs currently in use in patients with IBD}

Conventional therapies remain the cornerstone of treatment for the majority of patients with IBD, only a proportion of whom require biologic therapies. During recent years attention has been given to the optimization of conventional and biologic IBD therapies. Newer mesalazine formulations with a reduced pill size and only one dose per day demonstrate similar efficacy to older formulations. New corticosteroids (CSs) retain the efficacy of older CSs while exhibiting a higher safety profile. The role of antibiotics and probiotics has been further clarified. Finally, significant progress in understanding thiopurine metabolism has improved the effective dose along with adjunctive therapies.

Table 1 shows the drug categories currently used in the treatment of patients with IBD.

\section{Anti-inflammatory drugs Mesalazine}

Mesalazine, the active moiety of sulfasalazine, is available in specially formulated oral and rectal forms for the treatment of 
Table I Established drug categories used in the treatment of inflammatory bowel disease

\begin{tabular}{ll}
\hline Drug group & Drugs \\
\hline Anti-inflammatory & $\begin{array}{l}\text { - Mesalazine } \\
\text { - Corticosteroids (prednisolone, } \\
\text { methylprednisolone, butesonide) }\end{array}$ \\
Immunosuppressives & $\begin{array}{r}\text { - Azathioprine, 6-mercaptopurine, } \\
\text { methotrexate, cyclosporin, tacrolimus }\end{array}$ \\
Antibiotics & $\begin{array}{l}\text { Metronidazole, ornidazole, clarithromycin, } \\
\text { rifaximin ciprofloxacin, anti-TB }\end{array}$ \\
Probiotics & $\begin{array}{l}\text { Biologics } \\
\text { Bnfliximab, adalimumab, certolizumab pegol }\end{array}$ \\
\hline
\end{tabular}

Abbreviation: TB, tuberculosis.

active UC of mild to moderate severity and for maintenance therapy during disease remission.

The new preparations of mesalazine offer convenience and high dosage, while retaining their safety. New dosage regimens are likely to become standard practice in the near future. The drug might also act as a chemopreventive agent of colorectal cancer in the context of IBD, probably via the agonism of the peroxisome proliferator-activated receptor- $\gamma$ (PPAR- $\gamma)$. In future, even more effective agents based on mesalazine are expected, based on more powerful agonism of PPAR- $\gamma$. Mesalazine, either in tablets coated with acrylicbased resin or microgranules coated with ethylcellulose can be delivered to the distal small intestine and colon. ${ }^{7}$

\section{Mesalazine in ulcerative colitis}

Orally administered mesalazine represents an effective drug in the treatment of patients with mild to moderate active distal UC and for maintaining remission. In cases of distal UC mesalazine can also be administered rectally as a suppository, enema, or foam. ${ }^{8}$

Oral mesalazine in a dose of 1.5 to $2.4 \mathrm{~g}$ daily has similar efficacy to sulfasalazine 2 to $3 \mathrm{~g}$ daily in patients with mild to moderate UC. Mesalazine enemas once a day are more effective than placebo and apparently similar to enemas of prednisone $25 \mathrm{mg}$ or oral sulfasalazine $3 \mathrm{~g}$. Mesalazine $4 \mathrm{~g}$ enemas are more effective than enemas containing hydrocortisone $100 \mathrm{mg}$.

Once-daily dosing of delayed-release mesalazine at doses of 1.6 to $2.4 \mathrm{~g}$ /day was shown to be as effective as twice-daily dosing for maintenance of clinical remission in patients with $\mathrm{UC}$, thus increasing the compliance of the patients. ${ }^{9}$

Balsalazide disodium $1.1 \mathrm{~g}$ tablets administered as $3.3 \mathrm{~g}$ twice daily are effective, well-tolerated, and significantly better than placebo for improving signs and symptoms of mild-to-moderately active UC. ${ }^{10}$ Again, this new formulation is expected to significantly improve convenience and compliance of patients with active UC.
The ASCEND I study showed that delayed-release oral mesalazine is an effective and well-tolerated therapy in patients with mildly to moderately active UC, and a $4.8 \mathrm{~g} /$ day dose (Asacol ${ }^{\circledR}$ HD, 800-mg tablet; Procter and Gamble, Pharmaceuticals, Inc, Mason, $\mathrm{OH}$ ) may improve treatment success in patients with moderate disease compared with mesalazine $2.4 \mathrm{~g} /$ day (Asacol, 400-mg tablet). ${ }^{11}$

The ASCEND III study was designed to determine the efficacy and safety of mesalazine $4.8 \mathrm{~g}$ /day (Asacol HD, 800-mg tablet) compared with $2.4 \mathrm{~g} /$ day (Asacol, 400-mg tablet) in moderately active UC. The results showed that $70 \%$ of patients who received $4.8 \mathrm{~g} /$ day achieved treatment success at week 6 , compared with $66 \%$ of patients receiving 2.4 g/day. ${ }^{12}$

In a study aiming to determine the therapeutic equivalence and safety of once daily versus 3 times daily dosing of a total daily dose of $3 \mathrm{~g}$ mesalazine granules (Salofalk ${ }^{\circledR}$, Dr Falk Pharma GmBH, Freiburg, Germany) in patients with active $\mathrm{UC}$ it was shown that once daily $3 \mathrm{~g}$ mesalazine granules are as effective and safe as a three times daily of $1 \mathrm{~g}$ schedule. ${ }^{13}$

Most patients with mild-to-moderate UC who fail to achieve remission with up to 8 weeks' initial mesalazine therapy could achieve clinical and endoscopic remission following a further 8 weeks' treatment with high-dose MMX technology (Multi Matrix System) mesalazine therapy (Mezavant ${ }^{\mathbb{R}}$ tablet $1.2 \mathrm{~g}$; Shire, Dublin, Ireland). ${ }^{14}$

Two phase III studies have evaluated mesalazine with MMX technology in patients with active mild-to-moderate $\mathrm{UC}$ and shown it to be effective regardless of disease extent and severity, gender, and previous low-dose mesalazine therapy. ${ }^{15}$

\section{Conclusion}

Mesalazine is an effective drug in the treatment of mild-tomoderately active distal UC at a dose of 2.4 to $4.8 \mathrm{~g}$ /day. Once daily dosing should be the preferred application mode in active UC. The drug is generally well tolerated with few side-effects reported. However, patients must check their renal function at 6-month intervals. Mesalazine can also be tolerated by $85 \%$ of patients allergic to or intolerant of sulfasalazine. Side-effects of mesalazine enemas are confined to local irritation. ${ }^{16}$

\section{Mesalazine in Crohn's disease}

A recent meta-analysis evaluated the efficacy of aminosalicylates compared with placebo, CSs, and other aminosalicylates in active $\mathrm{CD} .{ }^{17}$ 
The results revealed that sulfasalazine was superior to placebo in inducing remission, with benefit confined mainly to patients with colitis, although it was less effective than CSs.

Low-dose mesalazine (1-2 g/day) did not differ from placebo and was less effective than CSs, while high-dose mesalazine (3-4.5 g/day) was not superior to placebo for induction of remission or response. Mesalazine could also be less effective than budesonide. ${ }^{17}$

Prevention of relapses in patients operated on for $\mathrm{CD}$ represent a rather difficult task. In a trial aiming to compare azathioprine (AZ) with mesalazine for the prevention of recurrence in patients with postoperative $\mathrm{CD}, \mathrm{AZ}$ did not show better results than mesalazine. ${ }^{18}$

\section{Conclusion}

The available data do not support a role for mesalazine in the treatment of active CD.

\section{Corticosteroids}

CSs suppress inflammation by blocking the early manifestations of inflammation, including enhanced vascular permeability, vasodilation, and infiltration by neutrophils as well as the later consequences of inflammation, including fibroblast activation, vascular proliferation, and deposition of collagen. CSs also influence immunological responses such as T-responses to antigens, downregulate production of inflammatory cytokines, and interfere with nuclear factor- $\kappa \mathrm{B}(\mathrm{NF}-\kappa \mathrm{B})$ production, thereby blunting inflammatory response. ${ }^{19}$

CSs can be administered orally, in the form of enemas, or systematically in conjunction with or without other drugs. The most widely used CSs are prednisolone, methylprednisolone, and budesonide.

\section{Corticosteroids in ulcerative colitis}

The dose and route of administration of CSs in active UC depends on the severity of the disease and ranges from 20 to 40 and 50 to $60 \mathrm{mg}$ /day for moderate and severe flare-ups, respectively. Subsequently, the dose should be reduced by 10 or $5 \mathrm{mg} /$ week depending on the clinical and endoscopic remission. ${ }^{20}$ In severe cases CSs should be given parenterally for at least 10 days. If there are no clinical or laboratory signs of improvement the patient must be treated with cyclosporin or biologic agents. CSs are not useful for maintenance treatment of UC.

Budesonide is an enteric-coated, locally acting CS, whose $\mathrm{pH}$ - and time-dependent coating enables its release into the ileum and ascending colon. There is no evidence to recommend the clinical use of oral budesonide for the induction of remission in active UC. ${ }^{21}$

\section{Corticosteroids in Crohn's disease}

CSs are highly effective drugs for induction of remission in patients with active $\mathrm{CD}$. The various formulations of CSs can induce fast remission, improving most of the symptoms in a few days, although they cannot achieve mucosal healing and they have a number of side-effects. In a Cochrane meta-analysis CSs were highly significantly more effective than placebo and mesalazine in inducing remission. It should be emphasized that although CSs cause more adverse events than either placebo or low-dose mesalazine, these adverse events did not lead to increased study withdrawal. ${ }^{22}$ Some patients could become steroid-dependend or steroid resistant. CSs are not useful for maintenance treatment of CD.

Budesonide treatment for up to 1 year is well tolerated, with an adverse-event profile similar to that of placebo. ${ }^{22}$ The 1-year relapse rates are low and not significantly different between patients treated with budesonide $6 \mathrm{mg}$ versus $9 \mathrm{mg} /$ day. Time to relapse and the number of adverse events are similar in both groups. ${ }^{14}$ Budesonide may be a safe option for treatment of CD during pregnancy. ${ }^{23}$

\section{Conclusion}

CSs remain the cornerstone of initial therapy in both active $C D$ and active UC. One-third of patients will fail to respond. Subsequent management of this proportion of patients involves decisions on whether to use cyclosporin or infliximab without compromising the health or safety of the patient, or to offer surgical treatment. Further studies are required in order to determine the optimal duration of treatment and tapering protocol as well as whether CSs are more effective in patients with certain phenotypes.

\section{Immunosuppressives}

Immunosuppressives are a group of drugs acting by inhibiting proliferation and activation of lymphocytes. In recent years the experience with AZ, 6-mercaptopurine (6-MP), methotrexate, cyclosporin, and tacrolimus has increased considerably. AZ is a prodrug that is converted to 6-MP. Subsequently 6-MP can be metabolized by thiopurine methyltransferase to an inactive metabolite, 6-methylmercaptopurine, or can be anabolized to two active metabolites, 6-thioguanine and 6-methylmeracaptopurine ribonucleotides. The therapeutic efficacy and the side-effects of $A Z$ are related to the serum levels of 6-thioguanine. A genetic polymorphism 
for thiopurine methyltransferase influences its activity. Low levels of thiopurine methyltransferase activity are associated with increased levels of 6-thioguanine, thus increasing both therapeutic efficacy and toxicity.

\section{Azathioprine and 6-mercaptopurine}

The optimal dose of AZ is 2 to $2.5 \mathrm{mg} / \mathrm{kg}$ bodyweight and of 6-MP 1 to $1.5 \mathrm{mg} / \mathrm{kg}$ bodyweight. The favorable results of the drug could appear after several (12 or more) weeks.

A recent analysis of eight randomized trials revealed that $\mathrm{AZ}$ and 6-MP were effective for inducing remission in active CD. Treatment longer than 17 weeks resulted in a better outcome. A steroid sparing effect was also seen. Adverse events requiring withdrawal from a trial were increased with active therapy. ${ }^{24}$

$\mathrm{AZ}$ and 6-MP are considered to be effective in approximately $40 \%$ of IBD patients after 5 years of treatment. According to recent data, one-quarter of the patients discontinued the drugs within 3 months, due to adverse events. If the results are favorable in the first months, the use of AZ could be extended over many years. ${ }^{25}$ It must be stressed that $\mathrm{AZ}$ withdrawal is associated with a high risk of relapse. If $\mathrm{AZ}$ is well tolerated, it should not be interrupted. ${ }^{26}$ Most experts agree that the concurrent use of mesalazine and $\mathrm{AZ}$ as induction or maintenance treatment in patients with IBD is justified. According to recent data the concomitant use of aminosalicylates and AZ offer much benefit to the patient. $^{27}$

\section{Methotrexate}

Experience with methotrexate is much less than with AZ. It can be used in patients with steroid-dependent or steroidrefractory $\mathrm{CD}$ for induction as well as maintenance of remission. ${ }^{28}$ Optimal dose and mode of application are still a matter of debate. The usual dose is $25 \mathrm{mg} /$ week for induction and 15 to $25 \mathrm{mg} /$ week for maintenance of remission, both applied subcutaneously (sc) or intramuscularly. ${ }^{29}$

In everyday clinical practice methotrexate is used mainly in patients who have failed treatment with $\mathrm{AZ}$ or who are intolerant to $\mathrm{AZ}$ and 6-MP. The effectiveness of the drug in fistulizing $\mathrm{CD}$ is weak. An old study did not prove that methotrexate is efficacious in UC patients. ${ }^{30}$ Current guidelines do not recommend its use in patients with UC.

\section{Tacrolimus}

Tacrolimus is a calcineurin inhibitor that suppresses proinflammatory cytokine production and T-cell activation. Side effects, such as nephrotoxicity, are dose-dependent although reversible with dose reduction or cessation of therapy.

The drug has been used in patients with fistulizing CD and refractory UC. Long-term administration seems to be an effective and well-tolerated treatment for patients with refractory UC. ${ }^{31}$ However, the reported results should be interpreted with caution due to the small number of patients treated. Topical tacrolimus has also been used to treat pyoderma gangrenosum and ulcerative proctitis with good results. ${ }^{32}$

In general, tacrolimus is a well-tolerated and useful drug that should be considered as an alternative agent in the treatment of IBD, especially in those who are intolerant or refractory to conventional immunosuppressives. ${ }^{33}$ However, more data are needed to determine the long-term efficacy and safety of tacrolimus.

\section{Cyclosporin}

Cyclosporin is a powerful immunosuppressive drug mainly used for the prevention of rejection in transplant patients. The drug has been used in patients with severe flare-ups of UC not responding to conventional treatment. Treatment with intravenous (iv) cyclosporin helps to avoid colectomy in a substantial proportion of patients with severe UC. ${ }^{34}$ In a relevant study in which iv cyclosporin at a dose of $5 \mathrm{mg} / \mathrm{kg}$ was administered to 18 patients with fulminant UC, $83 \%$ of patients responded to treatment. On follow-up at 2, 6, 12, and 24 months, the colectomy-free rates were $72 \%, 67 \%$, $61 \%$, and $56 \%$, respectively. ${ }^{35}$

The mechanisms of action of the drug are not yet fully understood. Cyclosporin was shown in experimental colitis to upregulate the expression of TGF- $\beta$ in the colonic tissue, enhance the expression of p-Smad2 and cFLIP in epithelial cells, and inhibit caspase- 8 activity, concurrently protecting from epithelial apoptosis associated with upregulation of TGF- $\beta$-related signaling. ${ }^{36}$

The adverse events are mild in most patients. However some adverse effects could be dangerous. The clinician must always follow up the patient appropriately by checking regularly drug serum levels.

\section{Side-effects of immunosuppressives}

In clinical practice AZ or 6-MP are not effective in one-third of patients. Up to $20 \%$ of patients discontinue therapy due to side-effects. Monitoring side-effects of immunosuppressives is mandatory for physicians treating IBD patients.

Thioguanins may have severe side-effects, the most important being various gastrointestinal symptoms, hepatotoxicity, 
and pancreatitis. Nodular regenerative hyperplasia is another important side-effect especially in men with CD after ileocecal resection. Methotrexate can induce myelosuppression, pulmonary fibrosis, and hepatic injury. Five milligrams of folic acid per week decreases gastrointestinal side effects without interfering with drug efficacy. Cyclosporin can cause renal dysfunction, tremor, hirsutism, hypertension, gum hyperplasia as well as gastrointestinal side-effects such as diarrhea, nausea, vomiting, hepatic disease, and, rarely, gastritis, and peptic ulcer. ${ }^{37}$

A trial of 6-MP should be considered in AZ intolerance, as half the patients tolerate a switch to 6-MP. Patients with hepatotoxicity or arthralgias and myalgias during AZ treatment might benefit more often than those with other types of adverse events. ${ }^{38}$ Allopurinol has been shown to reduce the metabolism of both AZ and 6-MP. The drug has been used along with reduced-dose thiopurine in an attempt to avoid adverse drug reactions. ${ }^{39}$

\section{Conclusion}

$\mathrm{AZ}$ and 6-MP are effective drugs for inducing remission in patients with active $\mathrm{CD}$ as well as for the maintenance of remission. The rate of response increases after 17 weeks of therapy. Recent data support the safety of AZ and 6-MP use in pregnancy and lactation. Thiopurine therapy in IBD is associated with an increased risk of lymphoproliferative disorders. $\mathrm{AZ}$ and 6-MP remain among the mainstays of IBD therapy.

\section{Antibiotics}

The rationale for using antibiotics in the treatment of IBD is based on the assumption that intestinal bacteria are involved in the pathogenesis of the disease. The terminal ileum and large bowel represent the areas most frequently affected by IBD and concurrently represent the sites with the highest bacterial concentrations. Pouchitis seems to be associated with bacterial overgrowth and dysbiosis.

Enteric flora is altered in patients with IBD and enteric bacteria can be found within the inflamed mucosa. There are indications suggesting that immunological tolerance to commensal bacteria has been lost in patients with IBD. Increased numbers of bacteroides, Escherichia coli, and enterococci, and decreased numbers of lactobacilli and bifidobacteria have been found in IBD patients. Finally, strong evidence from animal models suggests that the development of colitis is impossible in the absence of normal enteric flora. All these data support the assumption that manipulation of intestinal microbiota flora, with either antibiotics or probiotics, could be of benefit in patients with IBD.
Early studies claimed that a decrease in the mucosal peptide antibiotics (defensins) could be involved in the pathogenesis of IBD. Defensins are antimicrobial peptides produced at a variety of epithelial surfaces. Their main function is to maintain a balance between protection from pathogens and tolerance to normal flora. It has been suggested that attenuated expression of defensins compromises host immunity, thus altering the balance in favor of inflammation. This deficient induction may be due to changes in the intracellular transcription by NF- $\kappa \mathrm{B}$ and the intracellular peptidoglycan receptor NOD2. ${ }^{40}$ The beneficial effect of antibiotics in CD patients supports the assumption of the existence of an impaired mucosal antibacterial activity. ${ }^{41}$ However, recent reports suggest that defensin deficiency might be a consequence of mucosal surface destruction due to inflammatory process rather than a primary event, indicating that reduced defensin expression represents a consequence of the disease and not the real cause. ${ }^{42}$ Additional research is required in order to further clarify this interesting subject.

\section{Antibiotics in ulcerative colitis}

To date, relatively few trials on the use of antibacterial agents in UC patients have been carried out. Despite the fact that the results of these studies are not conclusive most clinicians have used antibiotics as an adjuvant therapy for severe UC.

Older studies showed that iv metronidazole in conjunction with CSs produced no better results compared with placebo plus CSs in inducing remission in patients with severe UC. ${ }^{43}$ It was reported that $74 \%$ of patients with acute relapse of UC who received CSs plus oral tobramycin achieved complete symptomatic remission while significantly fewer (43\%) patients who received CSs plus placebo achieved remission. ${ }^{44}$

Ciprofloxacin has also been tried in patients with UC with disappointing results. ${ }^{45}$ In order to overcome the disadvantages of their previous study on the route, duration, and dose of ciprofloxacin, the same authors described that iv ciprofloxacin was not effective as an adjunctive treatment to CSs in severe UC. ${ }^{46}$

Rifaximin was also investigated in patients with moderate-to-severe active UC refractory to steroid treatment. Patients received either rifaximin $400 \mathrm{mg}$ twice daily or placebo for 10 days as an adjunct to steroid treatment. No significant differences in clinical efficacy were found, although rifaximin significantly improved stool frequency, rectal bleeding, and sigmoidoscopic score. ${ }^{47}$

Two recently published studies have reported that combination treatment with antibiotics offers significant benefit 
in patients with active UC. In the first study the authors enrolled 25 patients. Patients received amoxicillin $500 \mathrm{mg}$ three times daily, tetracycline $500 \mathrm{mg}$ three times daily and metronidazole $250 \mathrm{mg}$ three times daily for 2 weeks as well as conventional treatment. At 3 and 12 months after antibiotic treatment, clinical activity indexes, and endoscopic and histological scores were significantly decreased compared with those before treatment. The clinical response rates in steroiddependent patients were $60 \%$ and $73.3 \%$ at 3 and 12 months, respectively, and $50 \%$ at 12 months in steroid-refractory patients. Among the steroid-dependent or refractory patients, $70.6 \%$ discontinued steroid therapy at 12 months. No serious drug-related toxicities were observed. ${ }^{48}$ In the second trial the authors investigated whether antibiotic combination induces and/or maintains remission of active UC. Patients with mildto-severe relapsing UC were assigned to oral amoxicillin $1500 \mathrm{mg} /$ day, tetracycline $1500 \mathrm{mg} /$ day, and metronidazole $750 \mathrm{mg} /$ day, versus placebo, for 2 weeks, and then followed up. This 2-week triple antibiotic therapy produced improvement, remission, and steroid withdrawal in active UC more effectively than the placebo. ${ }^{49}$

It seems that the subject of the role of antibiotics in UC is still open and further studies are required to better clarify their role in both active and inactive UC.

\section{Antibiotics in Crohn's disease}

During recent years an increased amount of research has been published on the use of broad-spectrum antibiotics in CD patients. The antibiotics used so far in patients with $C D$ include metronidazole, ornidazole, ciprofloxacin, tobramycin, clarithromycin, cotrimoxazole, and anti-TB treatment.

\section{Metronidazole}

Metronidazole has been investigated from the early 1970s. In a study conducted to test the efficacy and safety of the drug in CD patients, it was found that there was no difference between metronidazole and placebo-treated patients although a positive trend in favor of metronidazole was observed in patients with Crohn's colitis. ${ }^{50}$ In the National Cooperative Swedish Study, metronidazole was compared with sulfasalazine as a primary treatment for CD. Although no significant difference was found between the two groups, metronidazole was effective in patients who fail to respond to sulfasalazine. ${ }^{51}$

In another study, metronidazole was used either as a single therapy or in combination with cotrimoxazole and compared with cotrimoxazole alone and a double placebo in patients with a symptomatic relapse of CD. After 4 weeks' treatment there was no difference in response among the three treatment groups. ${ }^{52}$ In a subsequent study treatment with metronidazole for 16 weeks significantly decreased the CDAI, but no difference was found in the rates of remission compared with placebo. ${ }^{53}$

The potential for metronidazole $10 \%$ ointment to exert therapeutic benefit in perianal CD was recently evaluated. Patients received metronidazole $10 \%$ ointment, $0.7 \mathrm{~g}$ applied perianally three times daily, or placebo ointment. The mean reduction in perianal $\mathrm{CD}$ activity index score at 4 weeks did not differ between the two groups. However, more patients in the metronidazole group showed a reduction in Pediatric Crohn's Disease Activity Index of at least five points compared with the placebo group. Perianal discharge and perianal pain both declined significantly in the metronidazole-treated patients. Metronidazole $10 \%$ ointment was well tolerated, with minimal adverse effects. It could be used as a potential treatment for pain and discharge associated with perianal CD. ${ }^{54}$

Metronidazole has also been used in combination with other antibiotics. An antibiotic combination including $250 \mathrm{mg}$ metronidazole four times daily plus $500 \mathrm{mg}$ ciprofloxacin twice daily was compared with a standard steroid treatment for 12 weeks. The 2 treatments showed similar rates of remission, suggesting that this combination is a potential alternative to steroid treatment in the acute phase of CD. ${ }^{55}$ In another trial the combination of metronidazole and ciprofloxacin was supplemented with budesonide ( $9 \mathrm{mg}$ /day) for active CD. No difference was noticed compared with placebo, but the overall response in the two groups was lower than that in previous studies using budesonide, suggesting that antibiotic treatment is more effective in colonic disease than in isolated small bowel involvement. ${ }^{56}$

Unfortunately, the systematic administration of metronidazole is accompanied by important side-effects, including nausea, anorexia, dysgeusia, dyspepsia, and peripheral neuropathy, which limit its use in approximately $20 \%$ of patients.

\section{Ornidazole}

Ornidazole is a nitroimidazole derivate with a similar chemical structure and antimicrobial properties to metronidazole. Initially the efficacy of the drug was tested in a small number of patients with active $\mathrm{CD} .{ }^{57}$ In a subsequent study, 25 patients with active $\mathrm{CD}$ received $500 \mathrm{mg}$ /day of ornidazole for 4 weeks. $^{58}$ The results showed that the Crohn's Disease Activity Index (CDAI) declined significantly from week 0 to week 4, while the number of patients going into remission 
increased gradually from week 0 to week 4 . Presence and severity of abdominal pain decreased and bowel movements were reduced. General well-being improved significantly. An increase in bodyweight was noticed at the end of the fourth week. The drug also seems to reduce the recurrence rate,${ }^{59}$ while being quite safe ${ }^{60}$ In normal subjects ornidazole reduces the levels of serum $\mathrm{C}_{3} \cdot{ }^{61}$

\section{Ciprofloxacin}

Ciprofloxacin has been extensively used in patients with active CD with or without perineal involvement. In a study comparing ciprofloxacin $500 \mathrm{mg}$ twice daily with placebo twice daily for 6 months, the administration of ciprofloxacin significantly reduced CDAI score compared with placebo. ${ }^{62}$ In another study patients with a mild-to-moderate flare-up of CD were randomized to receive ciprofloxacin $1 \mathrm{~g}$ /day or mesalazine (Pentasa $^{\circledR}$; Shire) $4 \mathrm{~g} /$ day for 6 weeks. Complete remission was observed in $56 \%$ of patients treated with ciprofloxacin and in $55 \%$ of those treated with mesalazine. ${ }^{63}$ In an open study 72 patients with active $C D$ were treated with ciprofloxacin $500 \mathrm{mg}$ twice daily and metronidazole $250 \mathrm{mg}$ three times daily for 10 weeks. Clinical remission was observed in $68 \%$ of patients, and $76 \%$ showed clinical response. ${ }^{64}$

The drug has also been used in patients with fistulizing disease. In a relevant study, 25 patients with CD and actively draining perianal fistulas received ciprofloxacin $500 \mathrm{mg}$, metronidazole $500 \mathrm{mg}$, or placebo twice daily for 10 weeks. Remission and response was more frequent in patients treated with ciprofloxacin although the differences were not significant. ${ }^{65}$

Ciprofloxacin is an effective drug in a proportion of patients with active CD mainly located in the colon.

\section{Clarithromycin}

Clarithromycin is a broad-spectrum antibiotic that has good penetration into macrophages. Clarithromycin $1 \mathrm{~g}$ for 3 months was found to be ineffective in active CD although benefit was observed during the first month, suggesting that an initial effect may be attenuated by subsequent bacterial resistance. ${ }^{66}$

\section{Rifaximin}

Rifaximin is a rifamycin analog with a broad spectrum of activity. The drug has been used mainly on intestinal infections because it is an almost non-absorbed antibiotic from the gastrointestinal tract.

In an open-label study on the efficacy and safety of rifaximin $600 \mathrm{mg}$ /day for 16 weeks in patients with mild-to-moderate active CD, $59 \%$ of patients were in remission at the end of the study, with a significant reduction of the mean CDAI score compared with baseline. ${ }^{67}$

In another study patients with mild-to-moderate CD were randomized to three treatments for 12 weeks: rifaximin $800 \mathrm{mg}$ once daily plus placebo, rifaximin $800 \mathrm{mg}$ twice daily, and placebo twice daily. Remission and response rates of rifaximin $800 \mathrm{mg}$ twice daily were significantly higher than those of placebo and rifaximin $800 \mathrm{mg}$ once daily in patients with elevated C-reactive protein (CRP) values. Rifaximin $800 \mathrm{mg}$ twice daily was superior to placebo in inducing clinical remission. ${ }^{68}$

A recent experimental study suggested that the preventive and therapeutic role of rifaximin on IBD is probably achieved through human pregnane $\mathrm{X}$ receptor-mediated inhibition of the NF- $\mathrm{KB}$ signaling cascade. ${ }^{69}$

\section{Anti-TB treatment}

It has been suspected that Mycobacterium avium subsp. paratuberculosis, which causes Johne's disease, might also be a cause of CD.

In a prospective, parallel, placebo-controlled, double-blind, randomized trial of 2 years duration, 213 patients with active $\mathrm{CD}$ were randomized to clarithromycin $750 \mathrm{mg} /$ day, rifabutin $450 \mathrm{mg} /$ day, clofazimine $50 \mathrm{mg}$ /day or placebo, in addition to a 16-week tapering course of prednisolone. At week 16, there were significantly more subjects in remission in the antibiotic $\operatorname{arm}(66 \%)$ than the placebo arm (50\%). During the following year, no significant differences between antibiotic and placebo groups were noticed. The findings of this study do not support a significant role for $M$. avium subsp. paratuberculosis in the pathogenesis of $\mathrm{CD}$ in most patients. ${ }^{70}$

\section{Prevention of postoperative recurrence by antibiotics}

Antibiotics have also been studied in the prevention of postoperative disease recurrence of CD. Sixty patients were randomized to receive either metronidazole or placebo for 12 weeks. Metronidazole significantly reduced the incidence of severe endoscopic relapse and clinical recurrence rate. ${ }^{71}$ More recently, ornidazole used continuously for 1 year was shown to be more effective than placebo in the prevention of clinical and endoscopic recurrence in the neoterminal ileum. ${ }^{72}$

A recent study investigated whether metronidazole for 3 months together with AZ for 12 months was superior to metronidazole alone in reducing recurrence of postoperative $\mathrm{CD}$ in high-risk patients. Despite the enhanced risk of recurrence, the overall incidence of significant recurrence was rather low, probably owing to metronidazole treatment. Concomitant AZ resulted in lower endoscopic recurrence 
rates and less severe recurrences. ${ }^{73}$ Therefore this combined treatment seems to be reasonable for postoperative CD patients with an enhanced risk for recurrence.

\section{Conclusion}

The results of reported studies suggest that antibiotics are useful in the treatment of patients with CD. According to the opinion of many experts, incorporation of antibiotics into the therapeutic armamentarium for CD either as first-line therapy or in combination with immunosuppressive drugs might be a rational strategy. ${ }^{74}$ This assumption is further supported by the results of a recent meta-analysis which showed that long-term treatment with nitroimidazoles or clofazimine are effective in patients with $\mathrm{CD} .^{75}$

However significant questions remain to be answered. Why are only a small number of antibiotics useful in patients with IBD? What is the exact mode of action of metronidazole and ciprofloxacin? What is the role of concurrent infection (eg, Yersinia enterocolitica) in the course of CD? (We must bear in mind that ciprofloxacin is an effective drug against Yersinia spp.). In the near future, the answers to these questions could result in a more etiological therapeutic approach.

\section{Probiotics}

Probiotics are live non-pathogenic microorganisms administered to improve microbial balance in the gastrointestinal tract. They consist of Saccharomyces boulardii yeast or lactic acid bacteria, such as Lactobacillus and Bifidobacterium spp.

Probiotics exert their beneficial effects through various mechanisms, including reduced intestinal $\mathrm{pH}$, decreased colonization and invasion by pathogenic organisms, and modification of the host immune response. Lactobacillus paracase $i$ significantly decreases the plasma and lymphocyte content of proinflammatory cytokines in patients with UC. ${ }^{76}$ S. boulardii-secreted protein(s) inhibit production of proinflammatory cytokines by interfering with the global mediator of inflammation $\mathrm{NF}-\kappa \mathrm{B}$, and modulating the activity of the mitogen-activated protein kinases ERK1/2 and p38. It has also some other interesting properties, including activation of expression of PPAR- $\gamma$, suppression of 'bacteria overgrowth' and host cell adherence, release of protease that cleaves Clostridium difficile toxin $\mathrm{A}$, and stimulation of antibody production against toxin $\mathrm{A} .^{77}$

We must bear in mind, however, that probiotic benefits associated with one species or strain do not necessarily hold true for others. Also there is no consensus about the number of microorganisms that must be ingested to obtain a beneficial effect; however, a probiotic should typically contain several billion microorganisms to increase the chance of adequate gut colonization. ${ }^{78}$

\section{Probiotics in ulcerative colitis}

The administration of probiotics in patients with UC seems to be quite beneficial. The induction of remission in patients with active distal UC by $E$. coli Nissle $(\mathrm{EcN})$ administered in the form of enemas was investigated in a recent clinical trial. Patients were assigned to treatment with 40, 20, or $10 \mathrm{~mL}$ enemas containing $10 \mathrm{E} 8 \mathrm{EcN} / \mathrm{mL}$ or placebo once a day for 2 weeks. In the intention-to-treat analysis the number of responders was not significantly higher in the $\mathrm{EcN}$ group than in the placebo group, although the efficacy of rectal EcN was significant in the per-protocol analysis. ${ }^{79}$ The results support $\mathrm{EcN}$ as a well-tolerated alternative treatment in moderately active distal UC.

The use of probiotics in UC patients to maintain remission seems to be promising. VSL\# $3^{\circledR}$ (Sigma-Tau Pharmaceutics, Inc, Gaithersburg, MD) was shown to be a safe and effective modality in achieving clinical responses and remissions in patients with mild-to-moderately active UC. ${ }^{80}$ In a relevant study it was reported that the decrease in UC activity index scores (UCDAI) of $50 \%$ or more was significantly higher in the VSL\#3 group than in the placebo group (63.1 versus 40.8). Significant improvement with VSL\#3 in the UCDAI score and the degree of rectal bleeding was recorded. Remission rate was significantly higher in the VSL\#3 group than in the placebo group (47.7\% versus $32.4 \%$ ). VSL\#3 supplementation seems to be safe and able to reduce UCDAI score in patients with relapsing mild-to-moderate UC who are under treatment with mesalazine and/or immunosuppressants. ${ }^{81}$

Rembacken et al investigated whether the administration of a non-pathogenic strain of $\mathrm{EcN}$ was as effective as mesalazine in preventing relapse of $\mathrm{UC}$ as well as whether the addition of $E$. coli to standard medical therapy increased the rate of remission of active UC. The results showed that $75 \%$ of patients in the mesalazine group achieved remission compared with $68 \%$ in the $E$. coli group. In the mesalazine group, $73 \%$ of patients relapsed compared with $67 \%$ in the $E$. coli group (no significant differences). ${ }^{82}$ They concluded that treatment with a non-pathogenic $E$. coli is equally effective as mesalazine in maintaining remission of UC.

Lactobacillus rhamnosus GG strain alone or in combination with mesalazine decreased the relapse rate and significantly increased time to relapse compared to mesalazine alone. Bifidobacteria-fermented milk-supplemented patients with UC had significantly fewer exacerbations than non-supplemented patients. ${ }^{83}$ 


\section{Probiotics in Crohn's disease}

$\mathrm{CD}$ is characterized by increased intestinal permeability that permits antigen penetration into the intestinal tissue. In CD patients in remission, $S$. boulardii added to baseline therapy may improve the intestinal permeability. ${ }^{84}$ So far, none of the probiotics tested has been shown to be effective in induction of remission or in maintenance of remission in patients with $\mathrm{CD}$.

\section{Probiotics in pouchitis}

Probiotics are probably useful in inducing remission in active pouchitis. In a Cochrane systematic review it was suggested that oral probiotic therapy with VSL\#3 appears to be an effective therapy for maintaining remission in patients with chronic pouchitis in remission. ${ }^{85}$ However, because of the small number of patients tested the results must be interpreted with caution.

A multispecies probiotic mixture of eight strains seems to be helpful in maintaining remission in patients with pouchitis. ${ }^{86}$

\section{Conclusion}

Although probiotics are considered to be well tolerated, some adverse events, mainly bloating and flatulence, can occur. They should be used cautiously in patients who are critically ill or severely immunocompromised or in those with central venous catheters, since systemic infections may rarely occur. ${ }^{87}$ Administration of bacteria-derived probiotics should be separated from antibiotics by at least 2 hours. Because of the relatively small number of published trials, questions about optimal probiotic, optimal dosing, and specific patient populations to maintain remission remain to be answered.

\section{Biologic agents}

\section{Tumor necrosis factor alpha blocking strategies}

Because anti-TNF- $\alpha$ plays a pivotal role in the process of the inflammation in IBD patients, inhibition of this cytokine is expected to be a powerful treatment strategy in patients with both CD and UC. The available anti-TNF- $\alpha$ factors include infliximab, adalimumab, and certolizumab pegol. All these factors have been approved for use in the United States; however only the first two are licensed for use in Europe. All major gastroenterological associations recommend that treatment with anti-TNF- $\alpha$ monoclonal antibodies be considered in patients with moderate-to-severe $\mathrm{CD}$ refractory to concomitant aminosalicylates, CSs, or immunosuppressives, or patients who have contraindications to, or poor tolerance of, these agents. Infliximab has also been approved for the treatment of patients with severe UC not responding to conservative treatment.

\section{Infliximab}

Infliximab (IFX) has successfully been used in patients with CD or UC (Table 2).

\section{Infliximab in Crohn's disease}

IFX is an immunoglobulin G1 (IgG1) type chimeric monoclonal antibody against TNF- $\alpha$ which acts by binding to circulating and membrane-bound TNF- $\alpha$, inducing a cell mediated cytotoxic reaction and enhancing the programmed cell death of activated T-cells.

Studies on the use of IFX in either CD or UC are shown in Table 2. The ACCENT I study showed that treatment should be maintained in patients who responded to a single infusion of IFX ${ }^{88}$ and that maintenance therapy is superior to episodic administration while providing less anti-IFX antibody formation. ${ }^{89}$ Patients receiving systematic therapy also need fewer hospitalizations and less surgery. ${ }^{90}$

Healing of the mucosa has been shown to be a strong predictor of improved outcome of CD and anti-TNF- $\alpha$ therapy is a strong inducer of mucosal healing. ${ }^{91}$

IFX is also efficacious in fistulizing CD. In the study of Present et al, the primary end-point (a reduction of $50 \%$ or more from baseline in the number of draining fistulas) was achieved in $68 \%$ and $56 \%$ of patients treated with 5 and $10 \mathrm{mg} / \mathrm{kg}$ IFX at week 0,2 , and 6 , compared with $13 \%$ of the patients receiving placebo. The secondary end-point (closure of all fistulas) was achieved in 55\% of the patients assigned to receive $5 \mathrm{mg} / \mathrm{kg}$ of IFX and $38 \%$ of those assigned to $10 \mathrm{mg} / \mathrm{kg}$ compared with $13 \%$ of patients receiving placebo $\left(P=0.002\right.$ and $P=0.02$, respectively). ${ }^{92}$

The ACCENT II study demonstrated the efficacy of IFX in maintaining the good results in patients with perianal and enterocutaneous fistulae. The median time during which the patients were in remission was 14 and 40 weeks in the placebo and IFX groups, respectively. The remission rate was $36 \%$ in the IFX group compared with $19 \%$ in the placebo group. ${ }^{93}$

In a recent trial, the efficacy of IFX monotherapy, AZ monotherapy, and the two drugs combined was tested in 508 adults with moderate-to-severe CD. These patients had not undergone previous immunosuppressive or biologic therapy. Patients who were treated with IFX plus AZ or IFX monotherapy were more likely to have a corticosteroid-free clinical remission than those receiving $\mathrm{AZ}$ monotherapy. ${ }^{94}$

Timing of biological therapy is a matter of continuous debate. Early aggressive immunosupression seems to be the most efficacious therapeutic strategy in high-risk patients. In a meta-analysis it was found that early diagnosis, need for CS therapy at the first flare, and fistulizing behavior at the 
Table 2 Infliximab in either Crohn's disease or ulcerative colitis

\begin{tabular}{|c|c|c|c|c|}
\hline Study & Number of patients & Treatment schedule & Primary end-point & Response to treatment \\
\hline Accent $\left.\right|^{88}$ & $\mathrm{n}=573$ active $C D$ & $\begin{array}{l}5 \mathrm{mg} / \mathrm{kg} \text { single infusion } \\
5 \text { or } 10 \mathrm{mg} / \mathrm{kg} \text { maintenance } \\
\text { for those responded }\end{array}$ & $\begin{array}{l}\text { CDAI }>70 \text { points } 2 \text { weeks } \\
\text { response clinical remission } \\
54 \text { weeks }\end{array}$ & $\begin{array}{l}58 \% \\
28.3 \% \text { and } 38.4 \% \text { respectively } \\
\text { vs } 13.6 \% \text { of placebo }\end{array}$ \\
\hline Accent II ${ }^{93}$ & $\begin{array}{l}\mathrm{n}=306 \\
\text { Fistulizing CD }\end{array}$ & $5 \mathrm{mg} / \mathrm{kg}$ for those who responded & Week 54 absence of fistulas & $36 \%$ \\
\hline Ruggiero 160 & $\begin{array}{l}\mathrm{n}=24 \text { patients with } \\
\text { ileocolonic resection }\end{array}$ & $\begin{array}{l}\text { iv } 5 \mathrm{mg} / \mathrm{kg} \text { for } 12 \text { months } \\
\text { vs placebo }\end{array}$ & $\begin{array}{l}\text { Endoscopic and histologic } \\
\text { recurrence at I year }\end{array}$ & $\begin{array}{l}91 \% \text { and } 27.3 \% \text { (Infliximab) } \\
\text { vs } 84.6 \% \text { and } 84.6 \% \text { (placebo) }\end{array}$ \\
\hline Colombel $^{94}$ & $\begin{array}{l}\mathrm{n}=508 \text { patients with } \\
\text { moderate-severe } C D\end{array}$ & $\begin{array}{l}5 \mathrm{mg} \text { infliximab/kg at weeks } \\
0,2 \text {, and } 6 \text { and then every } \\
8 \text { weeks plus daily oral } \\
\text { placebo vs } 2.5 \mathrm{mg} \text { oral } \\
\text { azathioprine } / \mathrm{kg} \text { daily plus a } \\
\text { placebo infusion vs combination } \\
\text { of the } 2 \text { drugs. }\end{array}$ & $\begin{array}{l}\text { Corticosteroid-free clinical } \\
\text { remission at week } 26\end{array}$ & $\begin{array}{l}56.8 \% \text { (IFX plus AZ) vs } 44.4 \% \\
\text { (IFX + placebo) vs } 30.0 \% \\
\text { (AZ) (significant differences) }\end{array}$ \\
\hline Kohn 99 & $\begin{array}{l}\mathrm{n}=83 \text { patients with } \\
\text { severe UC }\end{array}$ & $\begin{array}{l}\text { Infliximab } 5 \mathrm{mg} / \mathrm{kg} \text { iv } \\
\text { (I or more infusions) }\end{array}$ & $\begin{array}{l}\text { Short-term outcome: colectomy/ } \\
\text { death } 2 \text { months after the first } \\
\text { infusion. } \\
\text { Long-term outcome: survival free } \\
\text { from colectomy }\end{array}$ & $\begin{array}{l}15 \% \text { underwent colectomy } \\
\text { after first infusion (greater } \\
\text { rates in patients receiving } \\
\text { only I infusion) }\end{array}$ \\
\hline ACT I and & $\mathrm{n}=364$ patients with & Placebo vs infliximab (5 or & Response: drop of Mayo $>3$ & \\
\hline ACT 2 studies ${ }^{96}$ & UC and Mayo score 6-12 & $\begin{array}{l}10 \mathrm{mg} / \mathrm{kg} \text { ) at weeks } 0,2 \text {, } \\
\text { and } 6, \text { then } 5 \mathrm{mg} / \mathrm{kg} / 8\end{array}$ & $\begin{array}{l}\text { rectal bleeding: } 0-1 \\
\text { ACT I }\end{array}$ & \\
\hline & & weeks through week 46 & Response week 8 & $69 \%$ \\
\hline & & $\begin{array}{l}\text { (ACT I) or through week } 22 \\
\text { (ACT 2) }\end{array}$ & $\begin{array}{l}\text { Response week } 54 \\
\text { ACT } 2\end{array}$ & $45 \%$ \\
\hline & & & Response week 8 & $64 \%$ \\
\hline & & & Response week 30 & $31 \%$ \\
\hline
\end{tabular}

Abbreviations: AZ, azathioprine; CD, Crohn's disease; CDAI, Crohn's disease activity index; IFX, infliximab; UC, ulcerative colitis.

time of the diagnosis were independent risk factors for an unfavorable disease course. ${ }^{95}$ Extended small bowel disease, upper gastrointestinal involvement, and smoking, also seem to represent risk factors for an unfavorable course.

\section{Infliximab in ulcerative colitis}

Two randomized, double-blind, placebo-controlled studies (ACT 1 and ACT 2), evaluated the efficacy of IFX for induction and maintenance therapy in patients with UC. Patients with a Mayo score of 6 to 12 points and moderate-to-severe active disease on sigmoidoscopy despite concurrent treatment with CSs alone or in combination with $\mathrm{AZ}$ or 6-MP in ACT 1 or despite concurrent treatment with CSs alone or in combination with $\mathrm{AZ}$ or 6-MP and mesalazine in ACT 2, were investigated. In ACT 1, 69\% and $61 \%$ of patients who received 5 or $10 \mathrm{mg} / \mathrm{kg}$ of IFX had a clinical response at week 8 , compared with $37 \%$ of those who received placebo. In ACT 2, clinical response at week 8 was noticed in 64\% and $69 \%$ of patients who received 5 or $10 \mathrm{mg} / \mathrm{kg}$ of IFX compared with $29 \%$ of those on placebo. ${ }^{96}$

The efficacy of IFX as a rescue therapy for severe to moderately severe UC not responding to iv steroid therapy has also been documented. In a relevant study significantly more patients treated with placebo required colectomy by 3 months compared with those treated with a single infusion of $5 \mathrm{mg} / \mathrm{kg}$ IFX.${ }^{97}$ Patients with moderate-to-severe UC treated with IFX were significantly less likely to undergo colectomy through 54 weeks than those receiving placebo. ${ }^{98}$ In the short term, two or more infusions seem to be more effective than a single infusion. ${ }^{99}$

\section{Adalimumab}

Adalimumab (ADA) is a fully human IgG1 type anti-TNF $\alpha$ monoclonal antibody that it is administered subcutaneously.

The CLASSIC-I trial investigated the efficacy of ADA for induction of remission in patients with CD. ${ }^{100} \mathrm{~A}$ total of 299 patients with moderate to severe $\mathrm{CD}$ naive to anti-TNF therapy received ADA $40 \mathrm{mg} / 20 \mathrm{mg}, 80 \mathrm{mg} / 40 \mathrm{mg}$, or $160 \mathrm{mg} / 80 \mathrm{mg}$ or placebo at weeks 0 and 2 . The rates of remission at week 4 in the ADA $40 \mathrm{mg} / 20 \mathrm{mg}, 80 \mathrm{mg} / 40 \mathrm{mg}$, and $160 \mathrm{mg} / 80 \mathrm{mg}$ groups were $18 \%, 24 \%$ and $36 \%$, respectively, in comparison with $12 \%$ in the placebo group. It was confirmed in this study that the optimal induction dosing regimen for ADA is $160 \mathrm{mg}$ at week 0 followed by $80 \mathrm{mg}$ at week 2 (Table 3 ). 
Table 3 Adalimumab in either Crohn's disease or ulcerative colitis

\begin{tabular}{|c|c|c|c|c|c|}
\hline Study & $\begin{array}{l}\text { Number of } \\
\text { patients }\end{array}$ & $\begin{array}{l}\text { Duration of } \\
\text { treatment }\end{array}$ & Comparisons & Primary end-point & $\begin{array}{l}\text { Response to } \\
\text { treatment }\end{array}$ \\
\hline CHARM study ${ }^{102}$ & $n=778$ & $3-12$ months & $\begin{array}{l}\text { Placebo vs adalimumab } \\
40 \mathrm{mg} \text { eow vs adalimumab } \\
40 \mathrm{mg} \text { weekly, all after an } \\
80 \mathrm{mg} / 40 \mathrm{mg} \text { adalimumab } \\
\text { induction regimen }\end{array}$ & $\begin{array}{l}\text { 3- and I2-month } \\
\text { hospitalization risks }\end{array}$ & $\begin{array}{l}\text { Less rates of hospitalization } \\
\text { and CD-related operations } \\
\text { in adalimumab group }\end{array}$ \\
\hline CLASSIC-I100 & $\begin{array}{l}\text { Moderate to } \\
\text { severe CD } \\
n=299\end{array}$ & $\begin{array}{l}\text { Adalimumab sc } 160 \text { and } \\
80 \mathrm{mg} \text { or } 80 \text { and } 40 \mathrm{mg} \\
\text { or } 40 \text { and } 20 \mathrm{mg} \text { at } \\
\text { week } 0 \text { and } 2\end{array}$ & & $\begin{array}{l}\text { Remission rate at } \\
\text { week } 4\end{array}$ & $\begin{array}{l}36 \% \\
24 \% \\
18 \%\end{array}$ \\
\hline CLASSIC-II'101 & $\begin{array}{l}\text { Patients from } \\
\text { Classic I } \\
\mathrm{n}=276\end{array}$ & $\begin{array}{l}40 \mathrm{mg} \text { : week } 0 \text { and } 2 \\
\text { and maintenance therapy } \\
40 \mathrm{mg} \text { eow or weekly } \\
\text { until week } 56\end{array}$ & & Remission rates & $\begin{array}{l}79 \% \\
83 \%\end{array}$ \\
\hline Colombel ${ }^{106}$ & $\mathrm{n}=11 \mathrm{I}$ & 56 weeks & $\begin{array}{l}\text { After induction treatment } \\
\text { patients at week } 4 \text {, were } \\
\text { assigned to double-blind } \\
\text { placebo or adalimumab } \\
40 \mathrm{mg} \text { eow or weekly } \\
\text { to week } 56\end{array}$ & $\begin{array}{l}\text { Healing of draining } \\
\text { fistulas in patients } \\
\text { with active } C D\end{array}$ & $\begin{array}{l}\text { Mean number of } \\
\text { draining fistulas/d } \\
\text { significantly decreased } \\
\text { in adalimumab-treated } \\
\text { patients }\end{array}$ \\
\hline Sandborn ${ }^{103}$ & $\begin{array}{l}\text { Loss of response } \\
\text { to IFX } \\
n=325\end{array}$ & $\begin{array}{l}\text { 4-week, double-blind, } \\
\text { placebo }\end{array}$ & $\begin{array}{l}160 \mathrm{mg} \text { and } 80 \mathrm{mg} \text { at } \\
\text { weeks } 0 \text { and } 2\end{array}$ & $\begin{array}{l}\text { Remission at week } 4 \\
\text { response }\end{array}$ & $\begin{array}{l}21 \% \text { in the adalimumab vs } \\
7 \% \text { of placebo. } \\
70 \text {-point response: } 52 \% \\
\text { in adalimumab vs } 34 \% \\
\text { of placebo }\end{array}$ \\
\hline Triantafillidis ${ }^{104}$ & $\mathrm{n}=30$ & $\begin{array}{l}\text { Patients either naive to } \\
\text { biologics or with response } \\
\text { loss or intolerance to IFX }\end{array}$ & & & $\begin{array}{l}\text { Remission in } 63.3 \% \\
\text { Clinical response in } 30 \%\end{array}$ \\
\hline Reinisch ${ }^{107}$ & $\mathrm{n}=390$ with UC & 8 weeks & $\begin{array}{l}\text { Adalimumab }(160 / 80 \text { or } \\
80 / 40) \text { vs placebo }\end{array}$ & Clinical remission & $\begin{array}{l}18.5 \% \text { vs } 9.2 \%(P=0.031) \\
10 \% \text { vs } 9.2 \%(N S)\end{array}$ \\
\hline
\end{tabular}

Abbreviations: CD, Crohn's disease; eow, every other week; IFX, infliximab; UC, ulcerative colitis.

The CLASSIC-II study evaluated the long-term efficacy and safety of ADA. ${ }^{101}$ Patients from CLASSIC-I study $(\mathrm{n}=276)$ were included and received open-label ADA $40 \mathrm{mg}$ at week 0 (week 4 of CLASSIC I) and week 2. Patients in remission at week 0 and 4 were re-randomized to ADA $40 \mathrm{mg}$ weekly or every other week (eow) or placebo until week 56. Non-remitting patients were randomized to open-label $40 \mathrm{mg}$ ADA eow Fifty-five of 276 patients achieved remission at week $4 ; 79 \%$ who received ADA $40 \mathrm{mg}$ eow and $83 \%$ who received $40 \mathrm{mg}$ weekly were in remission at week 56 , versus $44 \%$ for placebo. Of 204 patients who entered the open-label arm, $46 \%$ were in clinical remission at week 56 . Therefore, these two studies revealed that ADA is able to induce and maintain remission in $\mathrm{CD}$ patients.

A larger study (CHARM) evaluated the efficacy of adalimumab in the maintenance of response in $854 \mathrm{CD}$ patients. ${ }^{102}$ After an open-label induction therapy with $80 \mathrm{mg}$ (week 0) and $40 \mathrm{mg}$ (week 2) patients were randomized to $40 \mathrm{mg}$ ADA eow, $40 \mathrm{mg}$ ADA weekly or placebo maintenance therapy.
The percentage in remission was significantly greater in the ADA 40-mg eow and 40-mg weekly groups versus placebo at week $26(40 \%, 47 \%$, and $17 \%$, respectively) and week 56 (36\%, $41 \%$, and $12 \%$, respectively).

ADA induces remissions more frequently than placebo in adult patients with CD who cannot tolerate IFX or are symptomatic despite receiving IFX therapy. ${ }^{103}$ In a relevant study $21 \%$ of patients in the ADA group versus $7 \%$ of those in the placebo group achieved remission at week 4 . A 70-point response occurred at week 4 in 52\% of patients in the ADA group versus $34 \%$ of patients in the placebo group. Therefore, ADA is well tolerated and appears to be a beneficial option for patients with $\mathrm{CD}$ who have lost their response to or cannot tolerate IFX, for non-smokers, for patients with short duration of $\mathrm{CD}$, and for patients with extraintestinal manifestations who have a better clinical response. ${ }^{104}$ Moreover, patients with moderate-to-severe CD treated with ADA had lower 1-year risks of hospitalization and surgery than placebo patients. ${ }^{105}$ 
ADA has also excellent results in healing of draining fistulas in patients with active CD. ${ }^{106}$ It was found that the mean number of draining fistulas per day was significantly decreased in ADA-treated patients compared with placebotreated patients. ADA therapy was more effective than placebo for inducing fistula healing and complete fistula healing was sustained for up to 2 years by most patients.

\section{Adalimumab in ulcerative colitis}

The results on efficacy and safety of ADA for the induction of remission in anti-TNF naive patients with moderately to severely active UC were recently published. ${ }^{107} \mathrm{In}$ this study $18.5 \%$ of patients in the ADA $160 \mathrm{mg} / 80 \mathrm{mg}$ group ( $P=0.031$ versus placebo) and $10.0 \%$ in the ADA $80 \mathrm{mg} / 40 \mathrm{mg}$ group ( $P=0.833$ versus placebo) were in remission at week 8 , compared with $9.2 \%$ in the placebo group. Serious adverse events occurred in $7.6 \%, 3.8 \%$ and $4.0 \%$ of patients in the placebo, ADA $80 \mathrm{mg} / 40 \mathrm{mg}$, and ADA $160 \mathrm{mg} / 80 \mathrm{mg}$ groups, respectively. ADA was safe and effective for induction of clinical remission in patients with moderate to severely active UC failing treatment with CSs and/or immunosuppressants.

The efficacy of ADA in patients with UC who lost the response or became intolerant to IFX was also studied in a small number of patients. ${ }^{108}$ In an open-label study, ADA induction therapy with $160 \mathrm{mg} / 80 \mathrm{mg}$ resulted in remission at week 4 in four out of ten patients while three other patients improved.

In a more recent study on patients with UC who lost response to IFX, ADA achieved clinical response at weeks 4 and 12 in $53 \%$ and $60 \%$ of patients, respectively, and clinical remission in $10 \%$ and $27 \%$ of patients, respectively. After a mean 48 -week follow-up, $50 \%$ of patients continued on ADA. All patients who achieved clinical response at week 12 were colectomy free in the long term. ${ }^{109}$

\section{Certolizumab pegol}

Certolizumab pegol (CZP) is an antigen-binding fragment (Fab') portion of an IgG antibody attached to a $40-\mathrm{kDa}$ polyethylene glycol moiety to increase the $t_{1 / 2}$ of the treatment to approximately 2 weeks. The drug has been approved in the United States for use in patients with CD not responding to conventional treatment, while in Europe it is approved only in Switzerland for the treatment of CD (Table 4).

A phase II trial demonstrated the efficacy of a $400 \mathrm{mg}$ sc dose of the drug. ${ }^{110}$ Subsequently, the efficacy of CZP was evaluated in two studies (PRECiSE 1 and 2).
Patients with moderate-to-severe CD $(n=662)$ were randomly assigned to $400 \mathrm{mg}$ CZP or placebo at weeks 0 , 2, and 4. ${ }^{111}$ Maintenance therapy was administered every 4 weeks. Induction of remission as a primary end-point was evaluated at weeks 6 and 26. Response rates were higher in the CZP group than in the placebo group at both time points (35\% versus $27 \%$ and $23 \%$ versus $16 \%$, respectively). Patients with elevated CRP levels showed a more pronounced improvement.

In the PRECiSE 2 study the efficacy of maintenance therapy in 668 patients with moderate-to-severe $\mathrm{CD}$ was evaluated. ${ }^{112}$ Maintenance of response was significantly higher in the active treatment group (63\% versus $36 \%$ ).

The PRECiSE 3 study evaluated the long-term results of CZP administration. ${ }^{113}$ The observational period was 3.5 years. Long-term remission rates were observed in the PRECiSE 3 patients receiving CZP and specifically in patients with no previous exposure to other TNF inhibitors.

The WELCOME study revealed that location of CD, resection, number of resections, and baseline disease activity have a significant impact on the probability of achieving remission after 26 weeks of treatment. ${ }^{114}$

Evidence for mucosal healing has now been provided for CZP. ${ }^{115}$ Maintenance therapy with CZP resulted in significant and clinically meaningful improvements in health-related quality of life. Furthermore, a significant proportion of patients who received CZP returned to a normal life compared with those who received placebo. ${ }^{116}$

In a population of $\mathrm{CD}$ patients with perianal disease, $\mathrm{CZP}$ induced a response and remission rates in $54 \%$ and $40 \%$ of patients, respectively. The drug seems to be effective in perianal fistulizing $\mathrm{CD} .{ }^{117}$

Another study examined whether fistula closure is maintained at week 26 after treatment with CZP. It was found that at this time, $36 \%$ of patients in the CZP group had $100 \%$ fistula closure compared with $17 \%$ of patients receiving placebo $(P=0.038)$. It seems therefore that continuous treatment with CZP improves the likelihood of sustained perianal fistula closure compared with placebo. ${ }^{118}$

The published controlled trials regarding the use of CZP in the treatment of CD share similar limitations with other studies of TNF- $\alpha$ antagonists including high placebo response, natural course of disease fluctuation, and the use of CDAI to assess outcomes. However, CZP is considered to be an effective agent for adult patients with moderate-to-severe CD. CZP and ADA, unlike IFX, can be self-administered. With similarity in cost and the lack of head-to-head 
Table 4 Certolizumab in Crohn's disease

\begin{tabular}{|c|c|c|c|c|c|}
\hline Study & $\begin{array}{l}\text { Number of } \\
\text { patients }\end{array}$ & $\begin{array}{l}\text { Duration of } \\
\text { treatment }\end{array}$ & Comparisons & $\begin{array}{l}\text { Primary } \\
\text { end-point }\end{array}$ & $\begin{array}{l}\text { Response to } \\
\text { treatment }\end{array}$ \\
\hline $\begin{array}{l}\text { Schreiber }{ }^{1 / 8} \\
\text { PRECiSE } 2 \\
\text { subpopulation }\end{array}$ & $\begin{array}{l}\text { CZP } n=28 \\
\text { Fistulizing disease } \\
\text { Placebo } n=30\end{array}$ & 26 weeks & CZP vs placebo & closure of fistula & $\begin{array}{l}36 \% \text { vs } 17 \% \\
(P=0.038)\end{array}$ \\
\hline Schoepfer 117 & $\mathrm{n}=50$ & 6 weeks & $\begin{array}{l}\text { CZP } 400 \mathrm{mg} \text { sc } \\
\text { at weeks } 0,2 \text {, and } 4\end{array}$ & $\begin{array}{l}\text { Response and } \\
\text { remission rates }\end{array}$ & $\begin{array}{l}\text { Response }=54 \% \\
\text { Remission }=40 \% \\
\text { Effectiveness in } \\
\text { fistulizing disease }\end{array}$ \\
\hline Schreiber ${ }^{\prime 12}$ & $n=428$ & 26 weeks & $\begin{array}{l}\text { Induction therapy, } \\
400 \mathrm{mg} \text { CZP at weeks } \\
0,2 \text {, and } 4 \text {. Patients } \\
\text { with clinical response } \\
\text { received } 400 \mathrm{mg} \text { CZP } \\
\text { or placebo/4 weeks } \\
\text { through week } 24\end{array}$ & $\begin{array}{l}\text { Maintenance of } \\
\text { response through } \\
\text { week } 26 . \text { Baseline } \\
\text { CRP }>10 \mathrm{mg} / \mathrm{L}\end{array}$ & $\begin{array}{l}\text { Response was maintained through } \\
\text { week } 26 \text { in } 62 \% \text { of CZP vs } 34 \% \text { of } \\
\text { placebo, } P<0.00 \text { I) } \\
\text { Among patients with response } \\
\text { to induction therapy remission at } \\
\text { week } 26 \text { was seen in } 48 \% \text { of CZP vs } \\
29 \% \text { of placebo }(P<0.00 \text { I). }\end{array}$ \\
\hline Sandborn"'I & $\mathrm{n}=662$ & & $\begin{array}{l}\text { Patients were stratified } \\
\text { according to baseline } \\
\text { CRP. Treatment: } \\
\text { either } 400 \mathrm{mg} \text { of CZP or } \\
\text { placebo at weeks } 0,2 \text {, } \\
\text { and } 4 \text { and then every } \\
4 \text { weeks }\end{array}$ & & $\begin{array}{l}\text { Patients with CRP > } 10 \mathrm{mg} \text { : } \\
37 \% \text { in } C Z P \text { group had response } \\
\text { at week } 6, \text { vs } 26 \% \text { in the placebo } \\
\text { group ( } P=0.04) \text {. } \\
\text { At weeks } 6 \text { and } 26 \text {, the } \\
\text { corresponding values were } 22 \% \text { and } \\
12 \%(P=0.05) \text {. Overall, response } \\
\text { rates at week } 6: 35 \% \text { in CZP vs } 27 \% \\
\text { in placebo }(P=0.02)\end{array}$ \\
\hline
\end{tabular}

Abbreviations: CRP, C-reactive protein; CZP, certolizumab pegol.

comparisons, patient and physician preference may determine choice of TNF- $\alpha$ antagonist. ${ }^{119}$

\section{Side-effects of anti-TNF- $\alpha$ factors}

The most significant side-effects are related to opportunistic infections, malignancies, as well as injection/infusion reactions and appearance of autoimmunity. Contraindications include the presence of heart failure and acute infectious diseases. Clinicians should be aware that because of the powerful immunosuppressive capacity of biological agents, a rigorous and careful longterm safety follow-up should be adopted for all patients. ${ }^{120}$

A meta-analysis of anti-TNF trials evaluated the data of 21 studies involving 5356 patients (3341 patients in the anti-TNF groups and 2015 patients in the control groups). ${ }^{121}$ There was no difference in the frequency of death between the anti-TNF- $\alpha$ and control groups. Overall analysis of anti-TNF trials did not show any differences between anti-TNF- $\alpha$ and control groups in severe infections. Frequency of malignancies did not differ between treated and control groups. An increased number of hepatosplenic T-cell lymphoma in young patients highlighted the question of malignancies in patients treated with TNF- $\alpha$ inhibitors.

Both the US Food and Drug Administration and the European Crohn's and Colitis Organization categorize antiTNF agents as safe during pregnancy. ${ }^{122}$ Live-virus vaccines are generally contraindicated in patients receiving immunosuppressive regimens due to risks of vaccine-associated infection. While patients on immunosuppressives develop immune responses after vaccinations, these may be impaired relative to their non-immunosuppressed counterparts. ${ }^{123}$

Before starting treatment with biologic agents it is extremely important to assess patients' prior tuberculosis exposure by performing a tuberculin skin test (Mantoux test) and a chest X-ray, as the use of these biologic agents has been associated with reactivation of a latent tuberculosis. New IFN- $\gamma$ assays may enhance screening efficacy.

It has been proposed that a Mantoux test in patients with IBD (especially in patients with CD) seems to be meaningless based on the very high incidence of anergy in CD due to the disease itself, treatment with CSs, and poor nutritional status. ${ }^{124}$

According to data on patients with active UC, the incidence of anergy to the Mantoux test (16\%) did not differ from that in normal controls $(20 \%)$. On the other hand, in patients with active $\mathrm{CD}$ the incidence of anergy was significantly lower compared with normal people (20\% vs 52\%). ${ }^{125}$

We suggest that a Mantoux test must be performed both in all patients with active IBD, although in patients with CD a negative Mantoux test does not exclude the possibility of latent tuberculosis. ${ }^{126}$ 
Prophylaxis regimen will vary from country to country depending on resistance prevalence. In patients with a positive Mantoux test, isoniazide must be administered for 9 months. TNF- $\alpha$ antagonist should be started only after 1 month of treatment with isoniazide. Rifampicin for 4 months has also been suggested although it does not seem as good as an isoniazide regimen. We must bear in mind, however, that patients positive on screening who are treated with isoniazide and subsequently receive biologic agents still have an approximately $19 \%$ risk for tuberculosis. ${ }^{127}$

\section{Postsurgical treatment of patients with Crohn's disease with biologic agents}

CD commonly recurs after intestinal resection. Administration of IFX after intestinal resection for CD is effective in preventing endoscopic and histologic recurrence. In a small trial the rate of endoscopic recurrence at 1 year was significantly lower in the IFX group ( 1 of 11 patients; $9.1 \%$ ) than the placebo group (11 of 13 patients; 84.6\%). ${ }^{127}$ Larger studies may be desirable to strengthen the available data.

A thorough understanding of the mechanisms involved in the effectiveness of IFX in the postoperative setting could substantially improve our therapeutic strategies for overall patient management. ${ }^{128}$

\section{Conclusion}

The development of biologic agents and their use in IBD has improved patient quality of life considerably by modifying disease course and preventing complications and surgery. Control of inflammation can be achieved with all three available biologic agents, namely IFX, ADA, and CZP. These agents are effective in both induction and maintenance of remission. For fistula healing, both IFX and ADA are effective. Anti-TNF agents appear to be more effective in patients who have a shorter disease history and who have not yet been treated with any of these agents. Patients with CD who were treated with IFX plus AZ or IFX monotherapy are more likely to have a CS-free clinical remission than those receiving AZ monotherapy. Several strategies can minimize the risks associated with biologic therapies. Proper strategies include careful examination of past history and physical examination and screening for latent tuberculosis. During treatment, patients should be closely monitored. Education of physicians and patients is also important to allow the early detection of any adverse effect.

\section{Emerging therapeutic options for inflammatory bowel disease}

During recent years quite a large number of substances have been studied in patients with IBD. Apart from TNF- $\alpha$ inhibitors other molecules such as unfractionated or low-molecular-weight heparin, omega-3 polyunsaturated fatty acids, microbes, and microbial products have been studied. Leucocytapheresis, a method developed and applied mainly in Japan, also seems to be a promising therapeutic strategy.

The emerging therapeutic options for IBD are summarized below.

\section{New and emerging biologic agents}

So far, most patients with IBD are treated with rather unspecific medications exerting mainly anti-inflammatory or suppressive effects on the mucosal immune system. Although biologic agents directed against TNF- $\alpha$ represent an effective treatment, $30 \%$ of patients with $\mathrm{CD}$ will not respond to induction therapy, and of those who initially respond, 50\% will cease to respond within a year. During the last decade a better understanding of the underlying pathogenesis of IBD along with great advances in biotechnology has enabled the introduction of many biologic therapies, other than anti-TNF therapies, aiming to act on specific targets. ${ }^{129}$

We now can target many other proteins or receptors including the protein subunit $\mathrm{p} 40$ which heterodimerizes either with p35 resulting in the pro-inflammatory cytokine IL-12 or with p19, thus forming the pro-inflammatory IL-23, as well as antibodies that are able to block adhesion molecules in the areas of inflammation. Multiple genes that have been linked to alterations in immune pathways could also provide ways for understanding the pathogenesis of IBD and suggesting future drug targets. ${ }^{130}$ Many of these drugs have shown clinical benefit for induction and maintenance therapy in IBD, while others are under evaluation. Experimental data also indicate that pro-inflammatory cytokines play a significant role in promoting tumor development. The anti-cytokine agents could also be efficacious in preventing the onset of inflammation associated colorectal cancer. ${ }^{131}$

\section{Anti-adhesion (anti-integrin) molecules}

IBD is driven by the trafficking of lymphocytes from the circulation into the gut. Several endothelial adhesion molecules including E-selectin, ICAM-1, ICAM-2, VCAM-1, and mucosal addressin Mad-CAM-1, could enhance inflammation by trafficking leucocytes and recruiting immune 
cells into the gut. These molecules interact with integrins on leukocytes, thus inducing their migration from blood vessels into the site of inflammation.

The adhesion molecules involved represent attractive targets for the development of new drugs, which should aid in reducing existing inflammation and preventing recurrence of inflammation, and may lead to long-term control of disease. ${ }^{132}$

\section{Natalizumab}

Natalizumab is a humanized IgG4 monoclonal antibody that selectively targets the human $\alpha_{4}$-subunit, thus inhibiting both the VCAM-1/ $\alpha_{4} \beta_{1}$ and MAdCAM-1/ $\alpha 4 \beta 7$ pathways of leucocyte adhesion and transmigration. It has been approved for the treatment of patients with moderate-to-severe CD. This drug represents an efficacious therapeutic alternative for patients who do not respond to, or have failed, a TNF- $\alpha$ inhibitor.

In the most significant randomized placebo-controlled trial on the efficacy of natalizumab in CD, 509 patients were allocated to receive either $300 \mathrm{mg}$ natalizumab iv or placebo at weeks 0,4 , and 8 . Natalizumab induced response and remission at week 8 that was sustained through week 12 . Response and remission rates for natalizumab were superior to those for placebo at weeks 4,8 , and 12, demonstrating the early and sustained efficacy of the drug as induction therapy in patients with elevated CRP and active CD. ${ }^{133}$ Side-effects did not differ significantly between the two groups, although in the open-label extension of the study, one patient died because of progressive multifocal leukoencephalopathy.

\section{MLN-02}

MLN-02 is a humanized IgG1 monoclonal antibody against $\alpha 4 \beta 7$ integrin that selectively inhibits leukocyte adhesion in the gastrointestinal mucosa. Also, an Fc receptor recognition and binding has been detected, thus eliminating complement fixation and cytokine release.

In a recent study, patients with active $\mathrm{CD}$ were randomized to receive iv MLN-02 $2.0 \mathrm{mg} / \mathrm{kg}$, MLN-02 $0.5 \mathrm{mg} / \mathrm{kg}$, or placebo on days 1 and 29. Clinical response rates at day 57 were $53 \%, 49 \%$, and $41 \%$ in the MLN-02 $2.0 \mathrm{mg} / \mathrm{kg}$, MLN-02 $0.5 \mathrm{mg} / \mathrm{kg}$, and placebo groups while clinical remission rates at day 57 were $37 \%, 30 \%$, and $21 \%$, respectively ( $P=0.04$ for the $2.0 \mathrm{mg} / \mathrm{kg}$ versus placebo comparison). At day $57,12 \%$ and $34 \%$ of patients in the $2.0-$ and $0.5-\mathrm{mg} / \mathrm{kg}$ groups had clinically significant human anti-human antibody levels. This was suggestive of a dose-dependent beneficial effect of the drug on clinical remission. ${ }^{134}$
In a double-blind, placebo controlled trial, 181 patients with active UC received iv 0.5 or $2 \mathrm{mg} / \mathrm{kg}$ MLN-02 or placebo at day 1 and 29. Both doses of MLN-02 achieved better clinical and endoscopic response in patients compared with placebo. ${ }^{135}$

\section{Anti-ICAM-I therapy}

ICAM-1 seems to play a role in cell-mediated inflammation, specifically cell trafficking.

Alicaforsen (ISIS 2302) is an antisense to ICAM-1 (CD54) which was specifically designed to inhibit ICAM-1 expression. Theoretically, alicaforsen could be useful in the treatment of IBD patients.

Systemic treatment in CD patients revealed no significant results.

In UC patients, topical application in the form of enemas has demonstrated some effect in secondary outcomes, and initial studies in pouchitis are promising. The compound is well tolerated. ${ }^{136}$

\section{Anti-IL-6R antibodies \\ Tocilizumab}

Tocilizumab is a humanized anti-IL-6 receptor (IL-6R) monoclonal antibody which is produced using genetic engineering technology. Tocilizumab recognizes both the membrane-bound and the soluble form of IL-6R and specifically blocks IL-6 actions. As a consequence the drug is expected to be able to ameliorate inflammatory processes resulting from IL-6 overproduction.

The drug has been approved in the European Union for treatment of rheumatoid arthritis. It has also been studied for potential use in the treatment of CD. ${ }^{137}$

\section{Immunostimulators}

It has been suggested that some defects in the innate immune system may play an important role in the pathogenesis of CD. In the last 2 years a number of substances stimulating the innate immune system have been tested in patients with CD.

\section{Recombinant human granulocyte-macrophage} colony-stimulating factor (sargramostim)

Sargramostim is a recombinanthuman granulocyte-macrophage colony-stimulating factor (GM-CSF) that activates innate immunity.

In a randomized trial, 87 steroid-dependent $C D$ patients received sargramostim and 42 placebo. Significantly more sargramostim-treated patients achieved CS-free remission (18.6\% versus $4.9 \% ; P=0.03$ ) and improvement in 
health-related quality of life. However, patients who received sargramostim experienced in a greater degree musculoskeletal pain, injection site reactions, and dyspnea compared with placebo. ${ }^{138}$ In another study the subcutaneous administration of sargramostim at a dose of $6 \mu \mathrm{g} / \mathrm{kg} /$ day improved the CDAI score although only a minority of patients experienced clinical remission or clinical response. ${ }^{139}$ Finally, 124 patients with moderate/severe $\mathrm{CD}$ received $6 \mu \mathrm{g} / \mathrm{kg}$ of sargramostim sc or placebo daily for 56 days. Although the primary endpoint (reduction of the CDAI of at least 70 points at day 57) was not achieved, all secondary end-points were achieved. ${ }^{140}$ The drug must be further investigated.

\section{Recombinant human granulocyte-colony stimulating factor (filgrastin)}

Filgrastin, a recombinant human granulocyte-colony stimulating factor (G-CSF), has also been tested in CD. Twenty patients with active CD received daily $300 \mu \gamma \mathrm{rhu}$ G-CSF sc in a 12-week open-label study. At week 12, 25\% of patients achieved clinical remission while $55 \%$ and $35 \%$ achieved 70 and 100 point reductions in the CDAI score, respectively. There were no significant side-effects except mild bone pain. ${ }^{141}$

\section{Growth factors}

Human growth factors are signaling molecules that lead to ligand-specific signal transduction. Their downstream effects are associated with several cellular functions including epithelial healing in response to injury. Impaired epithelial repair represents an important pathophysiological event in IBD.

Specific growth factor deficiencies have been noted in patients with IBD. The mode of action of these factors seems to be related to reduction of bowel permeability and enhancement of mucosal healing.

Several growth factors including growth hormone, epidermal growth factor, keratinocyte growth factor, teduglutide, and GM-CSF/G-CSF have emerged as potential tools for the modulation of intestinal inflammation and repair. Despite promising results of initial studies, the evidence to justify treatment of patients is inadequate. Specifically, keratinocyte growth factor- 2 and epidermal growth factor did not show efficacy in phase II trials concerning patients with either CD or UC. ${ }^{142}$

\section{T-cell directed therapies}

In patients with IBD, T-cell-mediated immune responses directed against normal components of the gut flora play a significant role in amplifying and sustaining the mucosal inflammation by producing huge amounts of cytokines. Strategies aimed at interfering with T-cell accumulation and/or function in the gut have been employed with clinical success in patients with IBD. ${ }^{143}$

Therapeutic targets include modulators of CD80 or CD86-CD28 co-stimulatory signal (abatacept), CD2 receptors on T-cells (alefacept), CD11a, subunit of leukocyte function-associated antigen 1 (efalizumab), vitronectin receptor, and CD20 antigen on pre-B, immature, and mature $\mathrm{B}$ cells (rituximab). ${ }^{144}$

\section{Inhibitors of Th I polarization}

It has been shown that in patients with $C D$ the production of IL-12 and IL-18 results in Th1 polarized immune response and increased secretion of pro-inflammatory cytokines. It is logical therefore to test the efficacy of agents aiming to block the production of IL-12 and IFN- $\gamma$ in patients with CD.

\section{Anti-INF- $\gamma$ antibodies (fontolizumab)}

Fontolizumab is a humanized anti-IFN- $\gamma$ antibody that has been tested recently in patients with $\mathrm{CD}$. The administration of this antibody is based on the knowledge that elevated gut mucosal levels of INF- $\gamma$ are associated with disease symptoms.

A total of 201 patients with active CD was randomized to receive an initial iv dose of 1.0 or $4.0 \mathrm{mg} / \mathrm{kg}$ fontolizumab or placebo, followed by up to three sc doses of 0.1 or $1.0 \mathrm{mg} / \mathrm{kg}$ fontolizumab or placebo every 4 weeks. On day 29 response rates were similar in all treatment groups $(31 \%$ to $38 \%$ ). Subsequently a greater proportion of patients in the $1.0 \mathrm{mg} / \mathrm{kg}$ iv $/ 1.0 \mathrm{mg} / \mathrm{kg} \mathrm{sc}$ fontolizumab group achieved clinical response and greater improvement in the CDAI score compared with patients who received placebo. All fontolizumab groups had significant improvement in CRP levels. The frequency of adverse events was similar in all groups. ${ }^{145}$ Although a strong clinical response to fontolizumab was not observed, significant decrease in CRP levels suggest a biological effect.

\section{Anti IL- 12 antibodies (ustekinumab)}

Ustekinumab is a monoclonal antibody against the p40 subunit of IL-12/23, 2 important cytokines implicated in CD pathophysiology.

In a double-blind, cross-over trial 104 patients with moderate-to-severe $\mathrm{CD}$ were given sc placebo at weeks 0 to 3 , then ustekinumab at weeks 8 to 11 ; sc ustekinumab at weeks 0 to 3 , then placebo at weeks $8-11$; iv placebo at week 0 , then ustekinumab at week 8 ; or iv ustekinumab 
at week 0 , then placebo at week 8 . Clinical response rates for the combined groups given ustekinumab and placebo were $53 \%$ and $30 \%(P=0.02)$, respectively at weeks 4 and 6 , and $49 \%$ and $40 \%(P=0.34)$, respectively, at week 8 . In a subgroup of 49 patients who were previously given IFX, clinical response to ustekinumab was significantly greater than the group given placebo through week 8 . Furthermore, in an open-label trial on the effects of 4 weekly sc injections or one iv infusion of ustekinumab in 27 patients who were non-responders to IFX, the clinical responses at week 8 to sc and iv ustekinumab were $43 \%$ and $54 \%$, respectively. ${ }^{146}$ In a subsequent analysis of the alterations of levels of serum CRP the authors stressed that the potential benefit of ustekinumab in CD was further supported by serum CRP reduction. It seems that increased systemic inflammation as manifested by higher baseline CRP values leads to larger treatment effects with ustekinumab, especially in patients previously treated with IFX. ${ }^{147}$

\section{Apilimod}

Apilimod mesylate (formerly STA-5326) is an orally administered IL-12 and IL-23 inhibitor.

A phase II study evaluated the efficacy of the drug in treating 220 adult patients with CD. Patients received placebo or apilimod mesylate 50 or $100 \mathrm{mg}$ daily. A clinical response was experienced by $24.7 \%$ in the 50 -mg daily group and by $25.7 \%$ in the 100 -mg group, compared with $28.8 \%$ in the placebo group on day 29 (no significant differences). Apilimod did not demonstrate efficacy over placebo in patients with active CD. ${ }^{148}$

\section{Inhibitors of T-cell proliferation}

Selective blockade of lymphocyte-vascular endothelium interactions in the gastrointestinal tract seems to be a promising therapeutic strategy for IBD. A number of monoclonal antibodies have been developed and tested in patients with UC during recent years.

\section{Visilizumab}

Visilizumab is a humanized IgG2 monoclonal anti-CD3 antibody. In an open-label phase I study performed on patients with severe UC, 32 subjects who had not previously responded to a 5-day regime with iv $\mathrm{CSs}$ received visilizumab at a dose of 10 or $15 \mu \mathrm{g} / \mathrm{kg}$, on two consecutive days. On day $30,84 \%$ of patients demonstrated a clinical response, $41 \%$ achieved clinical remission, and 44\% achieved endoscopic remission; $45 \%$ of patients did not require salvage therapies or colectomy during the first year postdose. Mild to moderate symptoms of cytokine release occurred in $100 \%$ and $83 \%$ of patients in the 15 - and $10-\mu \mathrm{g} / \mathrm{kg}$ dose groups, respectively. All patients exhibited a decrease in circulating CD4(+) T-cell, which returned to baseline values by day 30 in 26 of 30 evaluable patients (86\%). There were no serious infections. Visilizumab had an acceptable safety profile at the $10-\mu \mathrm{g} / \mathrm{kg}$ dose level and may be clinically beneficial in patients with severe CS-refractory UC. ${ }^{149}$

In another study 104 patients were treated with visilizumab. The drug induced both symptomatic response and clinical response. Results with $5 \mu \mathrm{g} / \mathrm{kg} /$ day were similar to those observed with higher doses. However, all patients experienced adverse events. ${ }^{150}$

\section{Basiliximab}

Basiliximab is a chimeric IgG1 monoclonal antibody that targets CD25. This action is not associated with the release of cytokines because basiliximab has no cytoplasmic tail.

In an open-label, uncontrolled trial 20 patients with severe and moderate steroid-resistant UC were given a single dose of $40 \mathrm{mg}$ basiliximab plus standard steroid therapy. Within 8 weeks, 10 of $20(50 \%)$ patients achieved clinical remission. At 24 weeks, 13 of 20 (65\%) patients were in clinical remission. Five patients required colectomy. Treatment was well tolerated. ${ }^{151}$

Basiliximab appears to promote prolonged remission after a single treatment, and shows particular promise in moderate steroid-resistant UC.

\section{Daclizumab}

Daclizumab is a humanized IgG1 monoclonal antibody targeting CD25. In a double blind, placebo-controlled trial, 159 patients with active $\mathrm{UC}$ were randomized to receive induction therapy with daclizumab $1 \mathrm{mg} / \mathrm{kg}$ iv at weeks 0 and 4 , or $2 \mathrm{mg} / \mathrm{kg}$ iv at weeks $0,2,4$, and 6 , or placebo. Two percent of patients receiving daclizumab $1 \mathrm{mg} / \mathrm{kg}(P=0.11$ versus placebo) and $7 \%$ of patients receiving $2 \mathrm{mg} / \mathrm{kg}(P=0.73)$ were in remission at week 8 , compared with $10 \%$ of those who received placebo. Response occurred at week 8 in $25 \%$ of patients receiving daclizumab $1 \mathrm{mg} / \mathrm{kg}(P=0.04)$ and in $33 \%$ of patients receiving $2 \mathrm{mg} / \mathrm{kg}(P=0.30)$ versus $44 \%$ of those receiving placebo. Patients with moderate UC who are treated with daclizumab are not more likely to be in remission or response at 8 weeks than patients treated with placebo. ${ }^{152}$

\section{Anti-inflammatory cytokines}

Recombinant human IL- 10

In a recent meta-analysis aim to assess the efficacy and tolerability of IL-10 for induction of remission in patients with 
active $\mathrm{CD}$, no significant differences were found between the drug and placebo in complete remission or clinical remission. Patients treated with IL-10 were more likely to withdraw from the studies due to adverse events. Therefore, IL-10 does not appear to provide any benefit for the treatment of active CD. ${ }^{153}$

\section{Immunomodulators}

IFN- $\beta 1$ a has been shown to downregulate the expression of IL-12, a cytokine that is thought to be involved in mucosal degeneration in CD.

In a multicenter, double-blind, placebo-controlled, phase II, dose-finding study, patients with steroid-induced clinical remissions of $\mathrm{CD}$ were randomized $1: 1: 1: 1$ to $\mathrm{sc}$ IFN- $\beta 1 \mathrm{a}: 66 \mu \mathrm{g}$ three times weekly, $44 \mu \mathrm{g}$ three times weekly, $44 \mu \mathrm{g}$ twice weekly, or placebo three times weekly with steroid tapering. The study was terminated after a planned interim analysis at 26 weeks because there was no difference in efficacy between patients with $\mathrm{CD}$ receiving IFN- $\beta 1$ a or placebo. ${ }^{154}$

\section{Conclusion}

During the past decade a better understanding of the underlying pathogenesis of IBD along with great advances in biotechnology has resulted in the introduction of many biologic therapies, other than anti-TNF- $\alpha$. We now can target many other proteins or receptors including the protein subunit $\mathrm{p} 40$, as well as antibodies that are able to block adhesion molecules in the areas of inflammation.

Among the new biologic agents, natalizumab produced quite satisfactory results in patients with $\mathrm{CD}$ and is currently in regular use in the United States. However, attention must be given to the possible side-effects of the drug. A good suggestion is to use natalizumab as an alternative therapeutic option after failure or intolerance of other anti-TNF- $\alpha$ agents.

Results from trials on the use of antibodies against IL-12 and IL-6R in patients with CD produced relatively satisfactory results, although studies including large numbers of patients are needed. In patients with CS-refractory UC, basiliximab could be an effective agent.

We must stress the fact that so far no studies have compared head-to-head anti-TNF antibodies with other biological agents belonging to other classes such as natalizumab.

Despite promising results of the initial studies on the use of growth factors, the evidence to justify treatment of patients with $\mathrm{CD}$ is inadequate. Because the administration of anti-inflammatory cytokines or immunomodulators produced negative results their use at present is not justified.
Ustekinumab, the monoclonal antibody against the p40 subunit of IL-12/23, seems to be promising in patients with active $C D$, especially in those with high baseline CRP values.

Because the data on the efficacy and short- and long-term safety of these new biologic agents are limited, their use in IBD patients remains to be justified.

\section{Microbes and microbial products}

\section{Helminths}

In Western countries modern hygienic practices prevent exposure to parasitic worms. Epidemiologic studies suggest that people harboring infection from helminths are affected by immune-mediated disease to a lesser degree. Consequently, people living in less developed countries are probably protected from IBD development. This epidemiological assumption is further supported by experimental data showing that mice colonized with helminths are protected from the development of experimental colitis. ${ }^{155}$ The 'IBD hygiene hypothesis' states that raising children in extremely hygienic environments impairs immune development, which predisposes them to immunological diseases such as IBD later in life. ${ }^{156}$ Helminths stimulate immune regulatory circuitry by interacting with host innate and adoptive immunity, thus reducing aberrant inflammation.

It seems therefore that exposure to helminths may help prevent or even ameliorate IBD. The most important studies on the safety and possible efficacy of the intestinal helminth Trichuris suis in the treatment of patients with active CD are discussed below.

\section{Efficacy of helminths in Crohn's disease}

Twenty-nine patients with active CD ingested 2500 live T. suis ova every 3 weeks for 24 weeks. At week 24, 79.3\% responded and $72.4 \%$ remitted. Analysis at week 12 yielded similar results. ${ }^{157}$ There were no adverse events. Helminth therapy may offer a unique, safe, and efficacious alternative for CD management.

\section{Efficacy of helminths in ulcerative colitis}

In animal models, helminths prevent or improve colitis by inducing regulatory $\mathrm{T}$ cells and modulatory cytokines.

In a randomized, double blind, placebo-controlled trial aiming to determine the efficacy and safety of the helminth T. suis in UC, Summers et al assigned 54 patients with active UC, to receive $2500 \mathrm{~T}$. suis ova or placebo orally at 2 -week intervals for 12 weeks. After 12 weeks, improvement occurred in $43.3 \%$ of patients with ova treatment compared 
with $16.7 \%$ given placebo $(P=0.04)$. Treatment induced no side-effects. ${ }^{158}$

\section{Cholera toxin B subunit}

Cholera toxin B subunit has been shown to ameliorate experimentally induced colitis in mice.

In a recent study aim to evaluate the safety and efficacy of recombinant cholera toxin B subunit in CD patients, an oral solution of $5 \mathrm{mg}$ recombinant cholera toxin B subunit was administered to 15 patients with $\mathrm{CD}$ three times per week for 2 weeks. A significant decrease in CDAI score was observed. Response rates were $42 \%$ in the per-protocol analysis; $40 \%$ were in remission at 4 weeks and $30 \%$ at 8 weeks post-treatment. ${ }^{159}$ No significant side-effects were noted. Treatment with recombinant cholera toxin B subunit seems to be safe, leading to a $40 \%$ treatment response.

\section{Conclusion}

The results of these studies suggest that microbes and microbial products (especially ova therapy) could be a safe and effective therapy in patients with both active CD and active UC. However, we suggest that further studies including a large number of patients with different types of IBD are needed before considering helminth treatment as an alternative therapy for patients with IBD.

\section{Omega-3 free fatty acids}

Because of their anti-inflammatory action, omega-3 polyunsaturated fatty acids (PUFA) may be beneficial in IBD. A large body of evidence supports a protective effect of omega-3 PUFA in experimental animals and ex vivo models of CD and UC. Although fish oil supplementation in patients with IBD results in omega-3 PUFA incorporation into gut mucosal tissue and modification of inflammatory mediator profiles, the evidence of clinical benefits of omega-3 PUFA is weak. ${ }^{160}$

A study aim to determine whether the oral administration of omega-3 free fatty acids is more effective than placebo for prevention of relapse of CD showed that $4 \mathrm{~g}$ /day of omega- 3 free fatty acids for up to 58 weeks was not more effective in preventing relapse of $\mathrm{CD}$ than placebo. ${ }^{161}$

\section{Leukocytapheresis}

In patients with active IBD a large number of activated myeloid leucocytes infiltrate the colonic mucosa. Myeloid leucocytes produce large amounts of TNF- $\alpha$. It is possible, therefore, that selective granulocyte/monocyte adsorption could promote remission in active UC. The mode of action of granulocyte/monocyte adsorption appears to be more than adsorption of excess neutrophils and TNF-producing monocytes. Adsorbed granulocyte/monocytes release IL-1 receptor antagonist, hepatocyte growth factor, and soluble TNF receptors, which have anti-inflammatory properties. ${ }^{162}$

It is generally accepted that leukocytapheresis treatment of patients refractory to conventional UC therapy could produce very satisfactory results. ${ }^{163}$

More intensive leukocytapheresis seems to be more efficacious than weekly treatment. It can significantly reduce patient morbidity time without increasing the incidence of side-effects. ${ }^{164}$

\section{Unfractioned and low-molecular-weight heparin}

According to a recent meta-analysis on the use of unfractionated heparin and low-molecular-weight heparins (LMWH) in patients with active UC, sc LMWH showed no benefit over placebo. However, high doses of LMWH administered via an extended colon-release tablet demonstrated benefit over placebo for clinical remission and clinical and endoscopic improvement. There is evidence to suggest that LMWH may be effective for the treatment of active UC, a benefit that needs to be confirmed by randomized controlled studies. There is no evidence, however, to support the use of unfractionated heparin for the treatment of active UC. When deciding to administer LMWH in patients with active UC the benefit must be balanced against an increased risk of rectal bleeding. ${ }^{165}$

\section{Other substances}

\section{Anti-oxidants}

Oxidative stress plays a significant role in the pathogenesis of IBD. In a preliminary study it was reported that rectal d-alpha tocopherol enema (8000 U/day) may represent a novel therapy for mild and moderately active UC, probably owing to the anti-inflammatory and anti-oxidative properties of vitamin E. ${ }^{166}$

\section{Statins}

Experimental and clinical data have suggested that statins can downregulate both acute and chronic inflammatory processes. In a study including a small number of patients, atorvastatin therapy reduced inflammation in patients with $\mathrm{CD}$, thus encouraging further investigation in IBD patients. ${ }^{167}$

\section{Rosiglitazone}

Thiazolidinedione ligands for PPAR- $\gamma$ receptors have been proposed as novel therapies for UC. 
In a randomized, double-blind, placebo-controlled clinical trial the efficacy of rosiglitazone $4 \mathrm{mg}$ orally twice daily versus placebo twice daily for 12 weeks was studied in 105 patients with mild-to-moderate UC. Rosiglitazone was shown to be efficacious. ${ }^{168}$ In another study combined treatment with rosiglitazone and mesalazine achieved better results than mesalazine alone.

Rosiglitazone can alleviate colonic inflammation, which we hope will become a novel agent for UC treatment. ${ }^{169}$

\section{Drugs used in the treatment of pouchitis}

Pouchitis is the major long-term complication after ileal-pouch-anal anastomosis for UC. More than 15\% of operated patients can develop chronic pouchitis, either treatment-responsive or treatment-refractory. During recent years the treatment of refractory pouchitis has progressed significantly.

In a Cochrane systematic review on the efficacy of medical therapies for pouchitis it was found that ciprofloxacin was more effective in inducing remission than metronidazole. Lactobacillus GG were more effective than placebo, while budesonide enemas and metronidazole were similarly effective in inducing remission of the active disease. Other substances were also tried in patients with pouchitis (including glutamine and butyrate suppositories) but unfortunately produced no statistically significant results.

Bismuth carbomer foam enemas did not show efficacy, while VSL\#3 was more effective than placebo in maintaining remission of chronic pouchitis. For the prevention of pouchitis, allopurinol and inulin also seem to be of benefit. ${ }^{170}$

\section{Budesonide}

In an open-label study 20 patients with active pouchitis not responding after 1 month of antibiotic treatment were treated with budesonide controlled ileal release $9 \mathrm{mg}$ /day for 8 weeks; $75 \%$ achieved remission. Budesonide seems to be an important alternative treatment in this kind of patient. ${ }^{171}$

\section{Rifaximin}

In a placebo-controlled pilot study aiming to evaluate the efficacy and safety of rifaximin $400 \mathrm{mg}$ or placebo three times daily for 4 weeks in patients with active pouchitis, clinical remission occurred more frequently in patients treated with rifaximin but the difference was not significant in this pilot study. Further studies are required in order to determine if rifaximin is effective in active pouchitis. ${ }^{172}$

\section{Conclusion}

During the last decade we have seen the development of a large number of biological agents against TNF- $\alpha$, as well as many biochemical substances and molecules specifically for the medical treatment of patients with inflammatory bowel disease. This revolution was a consequence of significant advances in biotechnology along with an increased knowledge of the underlying pathophysiologic mechanisms of the disease. Among others, natalizumab has shown quite good results in $\mathrm{CD}$ patients while basiliximab has shown efficacy in steroid-refractory UC. Leukocytapheresis has shown satisfactory results in steroid-refractory patients with UC. Unfractionated heparin and LMWH have been studied in patients with active UC with encouraging results. Microbes and microbial products including eggs of helminths seem to reduce disease activity in patients with $\mathrm{UC}$ or $\mathrm{CD}$.

Helminths could act as adjuvants for induction of T regulatory cells which inhibit the maturation of CD4 T cells to Th1 and Th2 effector cells, and reduce the occurrence of Th1mediated diseases (such as CD) and Th2-mediated diseases (such as UC). Chronic helminth infestation provokes a state of chronic immune activation with anergy. Administration of ova of $T$. suis has given encouraging results in the treatment of CD and UC with a good safety record, but long-term trials are needed because of the potentially harmful effects of helminths on immunity.

Omega-3 fatty acids, antioxidants, statins and many other molecules are under investigation.

However, as stressed earlier, the true value of these new agents must not be overestimated, as their therapeutic success is limited and the costs per induced remission are quite high.

It is hoped that this enormous effort to discover new ways of treating IBD will make us more optimistic for the future of our patients suffering from this enigmatic disease.

\section{Acknowledgments}

Aikaterini Triantafillidis assisted by carrying out the literature search and making suggestions concerning the contents of this paper.

\section{Disclosure}

The authors report no conflicts of interest in this work.

\section{References}

1. Schirbel A, Fiocchi C. Inflammatory bowel disease: Established and evolving considerations on its etiopathogenesis and therapy. J Dig Dis. 2010;11(5):266-276. 
2. Danese S, Angelucci E. New and emerging biologics in the treatment of inflammatory bowel disease: quo vadis? Gastroenterol Clin Biol. 2009;33 Suppl 3:S217-S227.

3. Plevy S. The immunology of inflammatory bowel disease. Gastroenterol Clin North Am. 2002;31(1):77-92.

4. Liu ZJ, Yadav PK, Su JL, Wang JS, Fei K. Potential role of Th17 cells in the pathogenesis of inflammatory bowel disease. World J Gastroenterol. 2009;15(46):5784-5788.

5. Brand S. Crohn's disease: Th1, Th17 or both? The change of a paradigm: new immunological and genetic insights implicate Th17 cells in the pathogenesis of Crohn's disease. Gut. 2009;58(8):1152-1167.

6. Rivera-Nieves J, Gorfu G, Ley K. Leukocyte adhesion molecules in animal models of inflammatory bowel disease. Inflamm Bowel Dis. 2008;14(12):1715-1735.

7. Iacucci M, de Silva S, Ghosh S. Mesalazine in inflammatory bowel disease: a trendy topic once again? Can J Gastroenterol. 2010;24(2):127-133.

8. Marshall JK, Thabane M, Steinhart AH, Newman JR, Anand A, Irvine EJ. Rectal 5-aminosalicylic acid for induction of remission in ulcerative colitis. Cochrane Database Syst Rev. 2010;1:CD004115.

9. Sandborn WJ, Korzenik J, Lashner B, et al. Once-daily dosing of delayed-release oral mesalamine (400-mg tablet) is as effective as twice-daily dosing for maintenance of remission of ulcerative colitis. Gastroenterology. 2010;138(4):1286-1296.

10. Scherl EJ, Pruitt R, Gordon GL, et al. Safety and efficacy of a new $3.3 \mathrm{~g}$ b.i.d. tablet formulation in patients with mild-to-moderately-active ulcerative colitis: a multicenter, randomized, double-blind, placebocontrolled study. Am J Gastroenterol. 2009;104(6):1452-1459.

11. Hanauer SB, Sandborn WJ, Dallaire C, et al. Delayed-release oral mesalamine $4.8 \mathrm{~g}$ /day ( $800 \mathrm{mg}$ tablets) compared to $2.4 \mathrm{~g} /$ day (400 mg tablets) for the treatment of mildly to moderately active ulcerative colitis: The ASCEND I trial. Can J Gastroenterol. 2007;21(12):827-834.

12. Sandborn WJ, Regula J, Feagan BG, et al. Delayed-release oral mesalamine $4.8 \mathrm{~g} /$ day ( $800-\mathrm{mg}$ tablet) is effective for patients with moderately active ulcerative colitis. Gastroenterology. 2009;137(6):1934-1943.

13. Kruis W, Kiudelis G, Rácz I, et al. Once daily versus three times daily mesalazine granules in active ulcerative colitis: a double-blind, double-dummy, randomised, non-inferiority trial. Gut. 2009;58(2): 233-240.

14. Kamm MA, Lichtenstein GR, Sandborn WJ, et al. Effect of extended MMX mesalamine therapy for acute, mild-to-moderate ulcerative colitis. Inflamm Bowel Dis. 2009;15(1):1-8.

15. Lichtenstein GR, Kamm MA, Sandborn WJ, Lyne A, Joseph RE. MMX mesalazine for the induction of remission of mild-to-moderately active ulcerative colitis: efficacy and tolerability in specific patient subpopulations. Aliment Pharmacol Ther. 2008;27(11):1094-1102.

16. Brogden RN, Sorkin EM. Mesalazine. A review of its pharmacodynamic and pharmacokinetic properties, and therapeutic potential in chronic inflammatory bowel disease. Drugs. 1989;38(4):500-523.

17. Lim W-C, Hanauer S. Aminosalicylates for induction of remission or response in Crohn's disease. Cochrane Database Syst Rev. 2010;(12): CD008870. DOI: 10.1002/14651858.CD008870.

18. Reinisch W, Angelberger S, Petritsch W, et al. Azathioprine versus mesalazine for prevention of postoperative clinical recurrence in patients with Crohn's disease with endoscopic recurrence: efficacy and safety results of a randomised, double-blind, double-dummy, multicentre trial. Gut. 2010;59(6):752-759.

19. Ito K, Chung KF, Adcock IM. Update on glucocorticoid action and resistance. JAllergy Clin Immunol. 2006;117(3):522-543.

20. Truelove SC, Jewell DP. Intensive intravenous regimen for severe attacks of ulcerative colitis. Lancet. 1974;1(7866):1067-1070.

21. Lichtenstein GR, Bengtsson B, Hapten-White L, Rutgeerts P. Oral budesonide for maintenance of remission of Crohn's disease: a pooled safety analysis. Aliment Pharmacol Ther. 2009;29(6):643-653.

22. de Jong DJ, Bac DJ, Tan G, et al. Maintenance treatment with budesonide $6 \mathrm{mg}$ versus $9 \mathrm{mg}$ once daily in patients with Crohn's disease in remission. Neth J Med. 2007;65(9):339-345.
23. Beaulieu DB, Ananthakrishnan AN, Issa M, et al. Budesonide induction and maintenance therapy for Crohn's disease during pregnancy. Inflamm Bowel Dis. 2009;15(1):25-28.

24. Prefontaine E, Macdonald JK, Sutherland LR. Azathioprine or 6-mercaptopurine for induction of remission in Crohn's disease. Cochrane Database Syst Rev. 2010;16(6):CD000545.

25. Jharap B, Seinen ML, de Boer NK, et al. Thiopurine therapy in inflammatory bowel disease patients: analyses of two 8-year intercept cohorts. Inflamm Bowel Dis. 2010;16(9):1541-1549.

26. Treton X, Bouhnik Y, Mary JY, et al. Azathioprine withdrawal in patients with Crohn's disease maintained on prolonged remission: a high risk of relapse. Clin Gastroenterol Hepatol. 2009;7(1): 80-85.

27. Cassinotti A, Actis GC, Duca P, et al. Maintenance treatment with azathioprine in ulcerative colitis: outcome and predictive factors after drug withdrawal. Am J Gastroenterol. 2009;104(11):2760-2767.

28. Preiss JC, Zeitz M. Use of methotrexate in patients with inflammatory bowel diseases. Clin Exp Rheumatol. 2010;28(5 Suppl 61):S151-S155.

29. Patel V, Macdonald JK, McDonald JW, Chande N. Methotrexate for maintenance of remission in Crohn's disease. Cochrane Database Syst Rev. 2009;4:CD006884.

30. Oren R, Arber N, Odes S, et al. Methotrexate in chronic active ulcerative colitis: a double-blind, randomized, Israeli multicenter trial. Gastroenterology. 1996;110(5):1416-1421.

31. Yamamoto S, Nakase H, Mikami S, et al. Long-term effect of tacrolimus therapy in patients with refractory ulcerative colitis. Aliment Pharmacol Ther. 2008;28(5):589-597.

32. Lawrance IC, Copeland TS. Rectal tacrolimus in the treatment of resistant ulcerative proctitis. Aliment Pharmacol Ther. 2008;28(10): 1214-1220.

33. Baumgart DC, Macdonald JK, Feagan B. Tacrolimus (FK506) for induction of remission in refractory ulcerative colitis. Cochrane Database Syst Rev. 2008 Jul 16;3:CD007216.

34. Cheifetz AS, Stern J, Garud S, et al. Cyclosporin is safe and effective in patients with severe ulcerative colitis. J Clin Gastroenterol. 2011;45(2): 107-112.

35. Holme O, Thiis-Evensen E, Vatn MH. Treatment of fulminant ulcerative colitis with cyclosporin A. Scand J Gastroenterol. 2009;44(11): 1310-1314.

36. Satoh Y, Ishiguro Y, Sakuraba H, et al. Cyclosporin regulates intestinal epithelial apoptosis via TGF-beta-related signaling. Am J Physiol Gastrointest Liver Physiol. 2009;297(3):G514-G519.

37. Rogler G. Gastrointestinal and liver adverse effects of drugs used for treating IBD. Best Pract Res Clin Gastroenterol. 2010;24(2):157-165.

38. Hindorf U, Johansson M, Eriksson A, Kvifors E, Almer SH. Mercaptopurine treatment should be considered in azathioprine intolerant patients with inflammatory bowel disease. Aliment Pharmacol Ther. 2009;29(6):654-661.

39. Ansari A, Patel N, Sanderson J, O’Donohue J, Duley JA, Florin TH. Low-dose azathioprine or mercaptopurine in combination with allopurinol can bypass many adverse drug reactions in patients with inflammatory bowel disease. Aliment Pharmacol Ther. 2010;31(6): 640-647.

40. Wehkamp J, Fellermann K, Stange EF. Human deficins in Crohn's disease. Chem Immunol Allergy. 2005;86:42-54.

41. Ramasundara M, Leach ST, Lemberg DA, Day AS. Defensins and inflammation: the role of defensins in inflammatory bowel disease. J Gastroenterol Hepatol. 2009;24(2):202-208.

42. Fellerman K, Wehkamp J, Herrlinger KR, Stange EF. Crohn's disease: a defensin deficiency syndrome? Eur J Gastroenterol Hepatol. 2003; 15(6):627-634.

43. Chapman RW, Selby WS, Jewell DP. Controlled trial of intravenous metronidazole as an adjunct to corticosteroids in severe ulcerative colitis. Gut. 1986;27(10):1210-1212.

44. Burke DA, Axon AT, Clayden SA, Dixon MF, Johnston D, Lacey RW. The efficacy of tobramycin in the treatment of ulcerative colitis. Aliment Pharmacol Ther. 1990;4(2):123-129. 
45. Mantzaris GJ, Archavlis E, Christoforidis P, et al. A prospective randomized controlled trial of oral ciprofloxacin in acute ulcerative colitis. Am J Gastroenterol. 1997;92(3):454-456.

46. Mantzaris GJ, Hatzis A, Kontogiannis P, Triadaphyllou G. Intravenous tobramycin and metronidazole as an adjunct to corticosteroids in acute, severe ulcerative colitis. Am J Gastroenterol. 1994;89(1):43-46.

47. Gionchetti P, Rizzello F, Ferrieri A, et al. Rifaximin in patients with moderate or severe ulcerative colitis refractory to steroid-treatment: a doubleblind, placebo-controlled trial. Dig Dis Sci. 1999;44(6):1220-1221.

48. Uehara T, Kato K, Ohkusa T, et al. Efficacy of antibiotic combination therapy in patients with active ulcerative colitis, including refractory or steroid-dependent cases. J Gastroenterol Hepatol. 2010;25 Suppl 1:S62-S66.

49. Ohkusa T, Kato K, Terao S, et al. Newly developed antibiotic combination therapy for ulcerative colitis: a double-blind placebo-controlled multicenter trial. Am J Gastroenterol. 2010;105(8):1820-1829.

50. Blichfeldt P, Blomhoff JP, Myhre E, Gjone E. Metronidazole in Crohns disease. A double blind cross-over clinical trial. Scand J Gastroenterol. 1978;13(1):123-127.

51. Ursing B, Alm T, Barany F, et al. A comparative study of metronidazole and sulfasalazine for active Crohns disease: the cooperative Crohn's disease study in Sweden. II. Result. Gastroenterology. 1982;83(3):550-562.

52. Ambrose NS, Allan RN, Keighley MR, et al. Antibiotic therapy for treatment in relapse of intestinal Crohns disease. A prospective randomized study. Dis Colon Rectum. 1985;28(2):81-85.

53. Sutherland L, Singleton J, Sessions J, et al. Double blind, placebo controlled trial of metronidazole in Crohns disease. Gut. 1991; 32(9):1071-1075.

54. Maeda Y, Ng SC, Durdey P, et al. Topical Metronidazole in Perianal Crohn's Study Group. Randomized clinical trial of metronidazole ointment versus placebo in perianal Crohn's disease. Br J Surg. 2010; 97(9):1340-1347.

55. Prantera C, Zannoni F, Scribano ML, et al. An antibiotic regimen for the treatment of active Crohns disease: a randomized, controlled clinical trial of metronidazole plus ciprofloxacin. Am J Gastroenterol. 1996; 91(2):328-332.

56. Steinhart AH, Feagan BG, Wong CJ, et al. Combined budesonide and antibiotic therapy for active Crohns disease: a randomized controlled trial. Gastroenterology. 2002;123(1):33-40.

57. Triantafillidis JK, Manoussakis CA, Papavasiliou E. Ornidazole in the treatment of active Crohn's disease. Am J Gastroenterol. 1988;83(8): 892-893.

58. Triantafillidis JK, Nicolakis D, Emmanoullidis A, Antoniou A, Papatheodorou K, Cheracakis P. Ornidazole in the treatment of active Crohn's disease: short-term results. Ital J Gastroenterol. 1996;28(1): 10-14.

59. Triantafillidis JK, Antoniou A, Emmanoulidis A, Nicolakis D, Barbatzas C, Cheracakis P. Ornidazole in the prevention of recurrence of Crohn's disease. Ital J Gastroenterol Hepatol. 1998;30(4):446-447.

60. Triantafillidis JK, Nicolakis D, Antoniou A. Absence of toxicity of ornidazole after a 10-yr continous daily use for Crohn's disease. Am J Gastroenterol. 2001;96(1):254-255.

61. Triantafillidis JK, Hyphantis T, Driva G, et al. Ornidazole treatment in normal subjects reduces serum levels of C3. Dig Liver Dis. 2001;33(3): 302-303.

62. Arnold GL, Beaves MR, Pryjdun VO, Mook WJ. Preliminary study of ciprofloxacin in active Crohn's disease. Inflamm Bowel Dis. 2002;8(1): $10-15$.

63. Colombel JF, Lémann M, Cassagnou M, et al. A controlled trial comparing ciprofloxacin with mesalazine for the treatment of active Crohn's disease. Am J Gastroenterol. 1999;94(3):674-678.

64. Greenbloom SL, Steinhart AH, Greenberg GR. Combination ciprofloxacin and metronidazole for active Crohn's disease. Can J Gastroenterol. 1998;12(1):53-56.

65. Thia KT, Mahadevan U, Feagan BG, et al. Ciprofloxacin or metronidazole for the treatment of perianal fistulas in patients with Crohn's disease: a randomized, double-blind, placebo-controlled pilot study. Inflamm Bowel Dis. 2009;15(1):17-24.
66. Leiper K, Martin K, Ellis A, Watson AJ, Morris AI, Rhodes JM. Clinical trial: randomized study of clarithromycin versus placebo in active Crohn's disease. Aliment Pharmacol Ther. 2008;27(12):1233-1239.

67. Shafran I, Johnson LK. An open-label evaluation of rifaximin in the treatment of active Crohn's disease. Curr Med Res Opin. 2005;21(8): $1165-1169$.

68. Prantera C, Lochs H, Campieri M, et al. Antibiotic treatment of Crohn's disease: results of a multicentre, double blind, randomized, placebo-controlled trial with rifaximin. Aliment Pharmacol Ther. 2006; 23(8):1117-1125.

69. Cheng J, Shah YM, Ma X, et al. Therapeutic role of rifaximin in inflammatory bowel disease: clinical implication of human pregnane X receptor activation. J Pharmacol Exp Ther. 2010;335(1):32-41.

70. Selby W, Pavli P, Crotty B, et al. Antibiotics in Crohn's Disease Study Group. Two-year combination antibiotic therapy with clarithromycin, rifabutin, and clofazimine for Crohn's disease. Gastroenterology. 2007; 132(7):2313-2319.

71. Rutgeerts P, Hiele M, Geboes K, et al. Controlled trial of metronidazole treatment for prevention of Crohn's recurrence after ileal resection. Gastroenterology. 1995;108(6):1617-1621.

72. Rutgeerts P, Van Assche G, Vermeire S, et al. Ornidazole for prophylaxis of postoperative Crohns disease recurrence: a randomized, double-blind, placebo-controlled trial. Gastroenterology. 2005;128(4):856-861.

73. D'Haens GR, Vermeire S, Van Assche G, et al. Therapy of metronidazole with azathioprine to prevent postoperative recurrence of Crohn's disease: a controlled randomized trial. Gastroenterology. 2008; 135(4):1123-1129.

74. Greenberg GR. Antibiotics should be used as first-line therapy for Crohn's disease. Inflamm Bowel Dis. 2004;10(3):318-320.

75. Feller M, Huwiler K, Schoepfer A, Shang A, Furrer H, Egger M. Longterm antibiotic treatment for Crohn's disease: systematic review and meta-analysis of placebo-controlled trials. Clin Infect Dis. 2010;50(4): 473-480.

76. Federico A, Tuccillo C, Grossi E, et al. The effect of a new symbiotic formulation on plasma levels and peripheral blood mononuclear cell expression of some pro-inflammatory cytokines in patients with ulcerative colitis: a pilot study. Eur Rev Med Pharmacol Sci. 2009;13(4): 285-293.

77. Pothoulakis C. Review article: anti-inflammatory mechanisms of action of Saccharomyces boulardii. Aliment Pharmacol Ther. 2009;30(8): 826-833.

78. Williams NT. Probiotics. Am J Health Syst Pharm. 2010;67(6): 449-458.

79. Matthes H, Krummenerl T, Giensch M, Wolff C, Schulze J. Clinical trial: probiotic treatment of acute distal ulcerative colitis with rectally administered Escheria coli Nissle 1917 (EcN). BMC Complement Altern Med. 2010;10:13.

80. Sood A, Midha V, Makharia GK, et al. The probiotic preparation, VSL\#3 induces remission in patients with mild-to-moderately active ulcerative colitis. Clin Gastroenterol Hepatol. 2009;7(11): 1202-1209.

81. Tursi A, Brandimarte G, Papa A, et al. Treatment of relapsing mildto-moderate ulcerative colitis with the probiotic VSL\#3 as adjunctive to a standard pharmaceutical treatment: a double-blind, randomized, placebocontrolled study. Am J Gastroenterol. 2010;105(10):2218-2227.

82. Rembacken BJ, Snelling AM, Hawkey PM, Chalmers DM, Axon AT. Nonpathogenic Escherichia coli versus mesalazine for the treatment of ulcerative colitis: a randomised trial. Lancet. 1999;354(9179): 635-639.

83. Do VT, Baird BG, Kockler DR. Probiotics for maintaining remission of ulcerative colitis in adults. Ann Pharmacother. 2010;44(3):565-571.

84. Garcia Vilela E, De Lourdes De Abreu Ferrari M, Oswaldo Da Gama Torres $\mathrm{H}$, et al. Influence of Saccharomyces boulardii on the intestinal permeability of patients with Crohn's disease in remission. Scand J Gastroenterol. 2008;43(7):842-848.

85. Sandborn W, McLeod R, Jewell D. Pharmacotherapy for inducing and maintaining remission in pouchitis. Cochrane Database Syst Rev. 2000;2:CD001176. 
86. Haller D, Antoine JM, Bengmark S, Enck P, Rijkers GT, Lenoir-Wijnkoop I. Guidance for substantiating the evidence for beneficial effects of probiotics: probiotics in chronic inflammatory bowel disease and the functional disorder irritable bowel syndrome. J Nutr. 2010;140:690S-697S.

87. Riquelme AJ, Calvo MA, Guzmán AM, et al. Saccharomyces cerevisiae fungemia after Saccharomyces boulardii treatment in immunocompromised patients. J Clin Gastroenterol. 2003;36(1):41-43.

88. Hanauer SB, Feagan BG, Lichtenstein GR, et al. Maintenance infliximab for Crohn's disease: The ACCENT I randomized trial. Lancet. 2002;359(9317):1541-1549.

89. Rutgeerts P, Feagan BG, Lichtenstein GR, et al. Comparison of scheduled and episodic treatment strategies for infliximab in Crohn's disease. Gastroenterology. 2004;126(2):402-413.

90. Lichtenstein GR, Yan S, Bala M, Hanauer S. Remission in patients with Crohn's disease is associated with improvement in employement and quality of life and a decrease in hospitalizations and surgeries. $\mathrm{Am}$ J Gastroenterol. 2004;99(1):91-96.

91. Fidder HH, Hommes DW. Anti-TNF and Crohn's disease: when should we start? Curr Drug Targets. 2010;11(2):143-147.

92. Present DH, Rutgeerts P, Targan S, et al. Infliximab for the treatment of fistulas in patients with Crohn's disease. N Engl J Med. 1999;340(18): 1398-1405.

93. Sands BVDS, Bernstein C. Long-term treatment of fistulising Crohn's disease: response to Infliximab in the ACCENT II trial through 54 weeks. Gastroenterology. 2002;122:A81.

94. Colombel JF, Sandborn WJ, Reinisch W, et al. Infliximab, azathioprine, or combination therapy for Crohn's disease. $N$ Engl J Med. 2010;362(15):1383-1395.

95. Beaugerie L, Seksik P, Nion-Larmurier I, et al. Predictors of Crohn's disease. Gastroenterology. 2006;130(3):650-656.

96. Rutgeerts P, Sandborn WJ, Feagan BG, et al. Infliximab for induction and maintenance therapy for ulcerative colitis. $N$ Engl J Med. 2005; 353(23):2462-2476.

97. Jarnerot G, Hertervig E, Friis-Liby I, et al. Infliximab as rescue therapy in severe to moderately-severe ulcerative colitis: a randomized placebocontrolled study. Gastroenterology. 2005;128(7):1805-1811.

98. Sandborn WJ, Rutgeerts P, Feagan BG, et al. Colectomy rate comparison after treatment of ulcerative colitis with placebo or infliximab. Gastroenterology. 2009;137(4):1250-1260.

99. Kohn A, Daperno M, Armuzzi A, et al. Infliximab in severe ulcerative colitis: short-term results of different infusion regimens and long-term follow-up. Aliment Pharmacol Ther. 2007;26(5):747-756.

100. Hanauer SB, Sandborn WJ, Rutgeerts P, et al. Human anti-tumor necrosis factor monoclonal antibody (adalimumab) in Crohn's disease: the CLASSIC-I trial. Gastroenterology. 2006;130(2):323-333.

101. Sandborn WJ, Hanauer SB, Rutgeerts P, et al. Adalimumab for maintenance treatment of Crohn's disease: results of the CLASSIC-II trial. Gut. 2007;56(9):1232-1239.

102. Colombel JF, Sandborn WJ, Rutgeerts P, et al. Adalimumab for maintenance of remission in patients with Crohn's disease: the CHARM study. Gastroenterology. 2007;132(2):52-65.

103. Sandborn WJ, Rutgeerts P, Enns R, et al. Adalimumab induction therapy for Crohn disease previously treated with infliximab: a randomized trial. Ann Intern Med. 2007;146(12):829-838.

104. Triantafillidis JK, Mantzaris G, Karagiannis J, et al. Similar response to adalimumab in patients with active Crohn's disease either naive to biologic agents or with prior loss of response or intolerance to infliximab. Rev Med Chir Soc Med Nat Iasi. 2010;114(1): 85-90.

105. Feagan BG, Panaccione R, Sandborn WJ, et al. Effects of adalimumab therapy on incidence of hospitalization and surgery in Crohn's disease: results from the CHARM study. Gastroenterology. 2008;135(5): 1493-1499.

106. Colombel JF, Schwartz DA, Sandborn WJ, et al. Adalimumab for the treatment of fistulas in patients with Crohn's disease. Gut. 2009;58(7): 940-948.
107. Reinisch W, Sandborn WJ, Hommes DW, et al. Adalimumab for induction of clinical remission in moderately to severely active ulcerative colitis: results of a randomised controlled trial. Gut. 2011 Jan 5. [Epub ahead of print].

108. Peyrin-Biroulet L, Laclotte C, Roblin X, Bigard MA. Adalimumab induction therapy for ulcerative colitis with intolerance or lost response to infliximab: an open-label study. World $J$ Gastroenterol. 2007;13:2328-2332.

109. Taxonera C, Estellés J, Fernández-Blanco I, et al. Adalimumab induction and maintenance therapy for patients with ulcerative colitis previously treated with infliximab. Aliment Pharmacol Ther. 2011;33(3):340-348.

110. Schreiber S, Rutgeerts P, Fedorak RN, et al. A randomized, placebocontrolled trial of certolizumab pegol (CDP870) for treatment of Crohn's disease. Gastroenterology. 2005;129(3):807-818.

111. Sandborn WJ, Feagan BG, Stoinov S, et al. Certolizumab pegol for the treatment of Crohn's disease. N Engl J Med. 2007;357(3):228-238.

112. Schreiber S, Khaliq-Kareemi M, Lawrance IC, et al. Maintenance therapy with certolizumab pegol for Crohn's disease. $N$ Engl J Med. 2007;357(3):239-250.

113. Lichtenstein GTO, Schreiber S, Lawrance IC, Hanauer SB, Bloomfield R, Sandborn WJ. Long-term remission with Certolizumab pegol in Crohn's disease: Efficacy over 4 Years in patients with no prior TNF- $\alpha$ inhibitor exposure (Precise 3 Study). DDW 2010, New Orleans 2010:S1040.

114. Sandborn WJAM, D'Haens G, Colombel JF, et al. Predictors of Response and Remission to Certolizumab Pegol in Patients With Crohn's Disease: Data From the WELCOME Study. DDW 2010, New Orleans 2010:S1030.

115. van Assche G, Vermeire S, Rutgeerts P. Mucosal healing and anti TNFs in IBD. Curr Drug Targets. 2010;11(2):227-233.

116. Feagan BG, Coteur G, Tan S, Keininger DL, Schreiber S. Clinically meaningful improvement in health-related quality of life in a randomized controlled trial of certolizumab pegol maintenance therapy for Crohn's disease. Am J Gastroenterol. 2009;104(8):1976-1983.

117. Schoepfer AM, Vavricka SR, Binek J, et al. Efficacy and safety of certolizumab pegol induction therapy in an unselected Crohn's disease population: results of the FACTS survey. Inflamm Bowel Dis. 2010;16(6):933-938.

118. Schreiber S, Lawrance IC, Thomsen O Ø, Hanauer SB, Bloomfield R, Sandborn WJ. Randomised clinical trial: certolizumab pegol for fistulas in Crohn's disease - subgroup results from a placebo-controlled study. Aliment Pharmacol Ther. 2011;33(2):185-193.

119. Smith LS, Nelson M, Dolder CR. Certolizumab pegol: a TNF-\{alpha\} antagonist for the treatment of moderate-to-severe Crohn's disease. Ann Pharmacother. 2010;44(2):333-342.

120. Stallmach A, Hagel S, Bruns T. Adverse effects of biologics used for treating IBD. Best Pract Res Clin Gastroenterol. 2010;24(2): 167-182.

121. Peyrin-Biroulet L, Deltenre P, de Suray N, Branche J, Sandborn WJ, Colombel JF. Efficacy and safety of tumor necrosis factor antagonists in Crohn's disease: meta-analysis of placebo-controlled trials. Clin Gastroenterol Hepatol. 2008;6(6):644-653.

122. El Mourabet M, El-Hachem S, Harrison JR, Binion DG. Anti-TNF antibody therapy for inflammatory bowel disease during pregnancy: a clinical review. Curr Drug Targets. 2010;11(2):234-241.

123. Melmed GY. Vaccination strategies for patients with inflammatory bowel disease on immunomodulators and biologics. Inflamm Bowel Dis. 2009;15(9):1410-1416.

124. Rampton DS. Preventing TB in patients with Crohn's disease needing infliximab or other anti-TNF therapy. Gut. 2005;54(10):1360-1362.

125. Triantafillidis JK, Economidou J, Manousos ON, Efthymiou P. Cutaneous delayed hypersensitivity in Crohn's disease and ulcerative colitis. Application of multi-test. Dis Colon Rectum. 1987;30(7):536-539.

126. Triantafillidis JK, Georgopoulos F, Malgarinos G, Gikas A. Tuberculin test in patients with inflammatory bowel disease. Inflamm Bowel Dis. 2007;13(11):1451. 
127. Theis VS, Rhodes JM. Review article: minimizing tuberculosis during anti-tumour necrosis factor-alpha treatment of inflammatory bowel disease. Aliment Pharmacol Ther. 2008;27(1):19-30.

128. Sorrentino D, Paviotti A, Fiorino G. Anti-TNFs for postoperative recurrence in Crohn's disease: the if's and how's. Curr Drug Targets. 2010;11(2):219-226.

129. Fiorino G, Rovida S, Correale C, Malesci A, Danese S. Emerging biologics in the treatment of inflammatory bowel disease: what is around the corner? Curr Drug Targets. 2010;11(2):249-260.

130. Melmed GY, Targan SR. Future biologic targets for IBD: potentials and pitfalls. Nat Rev Gastroenterol Hepatol. 2010;7(2):110-117.

131. Triantafillidis JK. Kosmidis P, Nasioulas G. Colorectal cancer and inflammatory bowel disease: epidemiology, risk factors, mechanisms of carcinogenesis and prevention strategies. Anticancer Res. 2009;29(7):2727-2737.

132. Ghosh S, Panaccione R. Anti-adhesion molecule therapy for inflammatory bowel disease. Therap Adv Gastroenterol. 2010;3(4): 239-258.

133. Targan SR, Feagan BG, Fedorak RN, et al. Natalizumab for the treatment of active Crohn's disease: results of the ENCORE Trial. Gastroenterology. 2007;132(5):1672-1683.

134. Feagan BG, Greenberg GR, Wild G, et al. Treatment of active Crohn's disease with MLN0002, a humanized antibody to the alpha4beta7 integrin. Clin Gastroenterol Hepatol. 2008;6(12):1370-1377.

135. Feagan BG, Greenberg GR, Wild G, et al. Treatment of ulcerative colitis with a humanized antibody to alpha4beta7 integrin. $N$ Engl J Med. 2005;352(24):2499-2507.

136. Philpott JR, Miner PB Jr. Antisense inhibition of ICAM-1 expression as therapy provides insight into basic inflammatory pathways through early experiences in IBD. Expert Opin Biol Ther. 2008;8(10):1627-1632.

137. Venkiteshwaran A. Tocilizumab. MAbs. 2009;1(5):432-438.

138. Valentine JF, Fedorak RN, Feagan B, et al. Steroid-sparing properties of sargramostim in patients with corticosteroid-dependent Crohn's disease: a randomised, double-blind, placebo-controlled, phase 2 study. Gut. 2009;58(10):1354-1362.

139. Takazoe M, Matsui T, Motoya S, Matsumoto T, Hibi T, Watanabe M. Sargramostim in patients with Crohn's disease: results of a phase 1-2 study. J Gastroenterol. 2009;44(6):535-543.

140. Korzenic JR, Dieckgraefe BK, Valentine JF, Hausman DF, Gilbert MJ. Sargramostin for active Crohn's disease. N Engl J Med. 2005;352(21): 2193-2201.

141. Korzenic JR, Dieckgraefe BK. An open-labelled study of Granulocyte colony-stimulating factor in the treatment of active Crohn's disease. Aliment Pharmacol Ther. 2005;21(4):391-400.

142. Krishnan K, Arnone B, Buchman A. Intestinal growth factors: potential use in the treatment of inflammatory bowel disease and their role in mucosal healing. Inflamm Bowel Dis. 2011;17(1):410-422.

143. Monteleone G, Caprioli F. T-cell-directed therapies in inflammatory bowel diseases. Clin Sci (Lond). 2010;118(12):707-715.

144. Sharma R, Sharma CL, Mahajan A. Biological agents targeting beyond TNF-alpha. Indian J Crit Care Med. 2008;12(4):181-189.

145. Dotan I, Rachmilewitz D, Schreiber S, et al. Fontolizumab in moderate to severe Crohn's disease: a phase 2, randomized, double-blind, placebo-controlled, multiple-dose study. Inflamm Bowel Dis. 2010; 16(2):233-242.

146. Sandborn WJ, Feagan BG, Fedorak RN, et al. A randomized trial of Ustekinumab, a human interleukin-12/23 monoclonal antibody, in patients with moderate-to-severe Crohn's disease. Gastroenterology. 2008;135(4):1130-1141.

147. Toedter GP, Blank M, Lang Y, Chen D, Sandborn WJ, de Villiers WJ. Relationship of C-reactive protein with clinical response after therapy with ustekinumab in Crohn's disease. Am J Gastroenterol. 2009; 104(11):2768-2773.

148. Sands BE, Jacobson EW, Sylwestrowicz T, et al. Randomized, doubleblind, placebo-controlled trial of the oral interleukin-12/23 inhibitor apilimod mesylate for treatment of active Crohn's disease. Inflamm Bowel Dis. 2010;16(7):1209-1218.
149. Plevy S, Salzberg B, Van Assche G, et al. A phase I study of visilizumab, a humanized anti-CD3 monoclonal antibody, in severe steroid-refractory ulcerative colitis. Gastroenterology. 2007;133(5):1414-1422.

150. Baumgart DC, Targan SR, Dignass AU, et al. Prospective randomized open-label multicenter phase I/II dose escalation trial of visilizumab (HuM291) in severe steroid-refractory ulcerative colitis. Inflamm Bowel Dis. 2010;16(4):620-629.

151. Creed TJ, Probert CS, Norman MN, et al. Basiliximab for the treatment of steroid-resistant ulcerative colitis: further experience in moderate and severe disease. Aliment Pharmacol Ther. 2006;23(10): 1435-1442.

152. Van Assche G, Sandborn WJ, Feagan BG, et al. Daclizumab, a humanised monoclonal antibody to the interleukin 2 receptor (CD25), for the treatment of moderately to severely active ulcerative colitis: a randomised, double blind, placebo controlled, dose ranging trial. Gut. 2006;55(11):1568-1574.

153. Buruiana FE, Solà I, Alonso-Coello P. Recombinant human interleukin 10 for induction of remission in Crohn's disease. Cochrane Database Syst Rev. 2010;11:CD005109.

154. Pena Rossi C, Hanauer SB, Tomasevic R, Hunter JO, Shafran I, Graffner H. Interferon beta-1a for the maintenance of remission in patients with Crohn's disease: results of a phase II dose-finding study. BMC Gastroenterol. 2009;9:22.

155. Elliott DE, Weinstock JV. Helminthic therapy: using worms to treat immune-mediated disease. Adv Exp Med Biol. 2009;666:157-166.

156. Weinstock JV, Elliott DE. Helminths and the IBD hygiene hypothesis. Inflamm Bowel Dis. 2009;15(1):128-133.

157. Summers RW, Elliott DE, Urban JF Jr, Thompson R, Weinstock JV. Trichuris suis therapy in Crohn's disease. Gut. 2005;54(1): 87-90.

158. Summers RW, Elliott DE, Urban JF Jr, Thompson RA, Weinstock JV. Trichuris suis therapy for active ulcerative colitis: a randomized controlled trial. Gastroenterology. 2005;(4)128:825-832.

159. Stål P, Befrits R, Rönnblom A, et al. Clinical trial: the safety and short-term efficacy of recombinant cholera toxin B subunit in the treatment of active Crohn's disease. Aliment Pharmacol Ther. 2010; 31(3):387-395.

160. Ruggiero C, Lattanzio F, Lauretani F, Gasperini B, Andres-Lacueva C, Cherubini A. Omega-3 polyunsaturated fatty acids and immunemediated diseases: inflammatory bowel disease and rheumatoid arthritis. Curr Pharm Des. 2009;15(36):4135-4148.

161. Feagan BG, Sandborn WJ, Mittmann U, et al. Omega-3 free fatty acids for the maintenance of remission in Crohn disease: the EPIC Randomized Controlled Trials. JAMA. 2008;299(14):1690-1697.

162. Hanai H, Takeda Y, Eberhardson M, et al. The mode of actions of the Adacolumn therapeutic leucocytapheresis in patients with inflammatory bowel disease: a concise review. Clin Exp Immunol. 2011; 163(1):50-58.

163. Hibi T, Sameshima Y, Sekiguchi Y, Hisatome Y, et al. Treating ulcerative colitis by Adacolumn therapeutic leucocytapheresis: clinical efficacy and safety based on surveillance of 656 patients in 53 centres in Japan. Dig Liver Dis. 2009;41(8):570-577.

164. Sakuraba A, Motoya S, Watanabe K, et al. An open-label prospective randomized multicenter study shows very rapid remission of ulcerative colitis by intensive granulocyte and monocyte adsorptive apheresis as compared with routine weekly treatment. Am J Gastroenterol. 2009;104(12):2990-2995.

165. Chande N, McDonald JW, Macdonald JK, Wang JJ. Unfractionated or low molecular weight heparin for induction of remission in ulcerative colitis. Cochrane Database Syst Rev. 2010;10:CD006774.

166. Mirbagheri SA, Nezami BG, Assa S, Hajimahmoodi M. Rectal administration of d-alpha tocopherol for active ulcerative colitis: a preliminary report. World J Gastroenterol. 2008;14(39): 5990-5995.

167. Grip O, Janciauskiene S, Bredberg A. Use of atorvastatin as an antinflammatory treatment in Crohn's disease. Br J Pharmacol. 2008; 155(7):1085-1092. 
168. Lewis JD, Lichtenstein GR, Deren JJ, et al. Rosiglitazone for Ulcerative Colitis Study Group. Rosiglitazone for active ulcerative colitis: a randomized placebo-controlled trial. Gastroenterology. 2008; 134(3):688-695.

169. Liang HL, Ouyang Q. A clinical trial of combined use of rosiglitazone and 5-aminosalicylate for ulcerative colitis. World J Gastroenterol. 2008;14(1):114-119.

170. Holubar SD, Cima RR, Sandborn WJ, Pardi DS. Treatment and prevention of pouchitis after ileal pouch-anal anastomosis for chronic ulcerative colitis. Cochrane Database Syst Rev. 2010;6:CD001176.
171. Gionchetti P, Rizzello F, Poggioli G, et al. Oral budesonide in the treatment of chronic refractory pouchitis. Aliment Pharmacol Ther. 2007;25(10):1231-1236.

172. Isaacs KL, Sandler RS, Abreu M, et al. Rifaximin for the treatment of active pouchitis: a randomized, double-blind, placebo-controlled pilot study. Inflamm Bowel Dis. 2007;13(10):1250-1255.

\section{Publish your work in this journal}

Drug Design, Development and Therapy is an international, peerreviewed open-access journal that spans the spectrum of drug design and development through to clinical applications. Clinical outcomes, patient safety, and programs for the development and effective, safe, and sustained use of medicines are a feature of the journal, which has also been accepted for indexing on PubMed Central. The manuscript management system is completely online and includes a very quick and fair peer-review system, which is all easy to use. Visit http://www.dovepress.com/testimonials.php to read real quotes from published authors.

Submit your manuscript here: http://www.dovepress.com/drug-design-development-and-therapy-journal 